\title{
Follistatin Improves Skeletal Muscle Healing after Injury and Disease through an Interaction with Muscle Regeneration, Angiogenesis, and Fibrosis
}

\author{
Jinhong Zhu, ${ }^{* \dagger}$ Yong $\mathrm{Li},{ }^{\text {*‡§ }}$ Aiping Lu, ${ }^{* \ddagger}$ \\ Burhan Gharaibeh, ${ }^{* \neq}$ Jianqun Ma, ${ }^{* \neq \S \uparrow}$ \\ Tetsuo Kobayashi, ${ }^{* \ddagger}$ Andres J. Quintero, ${ }^{* \ddagger}$ \\ and Johnny Huard ${ }^{\star \dagger}$ \\ From the Stem Cell Research Center," University of Pittsburgh, \\ Pittsburgh, Pennsylvania; the Departments of Bioengineering ${ }^{\dagger}$ \\ and Orthopaedic Surgery, ${ }^{\ddagger}$ and the Laboratory of Molecular \\ Pathology, Department of Pathology, ${ }^{\S}$ University of Pittsburgh, \\ Pittsburgh, Pennsylvania; and the Division of Thoracic Surgery, "T \\ The Affiliated Tumor Hospital of Harbin Medical University, \\ Harbin, China
}

Recovery from skeletal muscle injury is often incomplete because of the formation of fibrosis and inadequate myofiber regeneration; therefore, injured muscle could benefit significantly from therapies that both stimulate muscle regeneration and inhibit fibrosis. To this end, we focused on blocking myostatin, a member of the transforming growth factor- $\beta$ superfamily and a negative regulator of muscle regeneration, with the myostatin antagonist follistatin. In vivo, follistatin-overexpressing transgenic mice underwent significantly greater myofiber regeneration and had less fibrosis formation compared with wild-type mice after skeletal muscle injury. Follistatin's mode of action is likely due to its ability to block myostatin and enhance neovacularization. Furthermore, muscle progenitor cells isolated from follistatin-overexpressing mice were significantly superior to muscle progenitors isolated from wild-type mice at regenerating dystrophin-positive myofibers when transplanted into the skeletal muscle of dystrophic $\mathrm{mdx} /$ severe combined immunodeficiency mice. In vitro, follistatin stimulated myoblasts to express MyoD, Myf5, and myogenin, which are myogenic transcription factors that promote myogenic differentiation. Moreover, follistatin's ability to enhance muscle differentiation is at least partially due to its ability to block myostatin, activin $A$, and transforming growth factor- $\beta 1$, all of which are negative regulators of muscle cell differentiation. The findings of this study suggest that follista- tin is a promising agent for improving skeletal muscle healing after injury and muscle diseases, such as the muscular dystrophies. (Am J Pathol 2011, 179:915-930; DOI: 10.1016/j.ajpath.2011.04.008)

Although skeletal muscle injuries are extremely common, accounting for up to $35 \%$ to $55 \%$ of all sports-related injuries, the treatments that are currently available have not progressed during the last few decades and are often ineffective. Unfortunately, significant morbidity is associated with these injuries, such as the development of painful contractures, loss of muscle extensibility and strength, and the increased risk for repeated injury, which is largely due to extensive fibrosis formation. In response to traumas and disease, the local secretion of transforming growth factor (TGF)- $\beta 1$, a potent fibrotic cytokine, induces the formation of fibrosis in various tissues and organs, including skeletal muscles. ${ }^{1-9}$ Various agents, including suramin, ${ }^{10,11}$ interferon- $\gamma,{ }^{12}$ decorin, ${ }^{5,8,13-15}$ relaxin, ${ }^{16,17}$ and losartan, ${ }^{9,18}$ have been shown to significantly enhance skeletal muscle regeneration, reduce fibrosis in injured muscles, and, in a broad spectrum of myopathic diseases, partially block TGF- $\beta 1$. Although

Supported in part by funding from the Henry J. Mankin Endowed Chair for Orthopaedic Research at the University of Pittsburgh, the William F. and Jean W. Donaldson Chair at Children's Hospital of Pittsburgh, the Hirtzel Foundation, the National Institutes of Health (R01 AR47973), and the US Department of Defense (W81XWH-06-1-0406).

Accepted for publication April 5, 2011.

Disclosures: J.H. received remuneration for consulting work performed for Cook Myosite Inc. during the period when this study was conducted and received royalties from Cook Myosite Inc. during this period. None of the other authors have any potential conflicts of interest to disclose.

Supplemental material for this article can be found at http://ajp. amjpathol.org or at doi: 10.1016/j.ajpath.2011.04.008

Current address of J.Z., Genomic Medicine Institute, Cleveland Clinic, Cleveland, Ohio

Address reprint requests to Johnny Huard, Ph.D., Department of Orthopaedic Surgery, University of Pittsburgh, Stem Cell Research Center, Bridgeside Point II, 450 Technology Dr., Pittsburgh, PA 15219. E-mail: jhuard@pitt.edu. 
much of the pathogenesis after skeletal muscle injury has been attributed to TGF- $\beta 1$ expression, it has become clear that myostatin, a member of the TGF- $\beta$ superfamily, can also be implicated in the formation of muscle fibrosis. ${ }^{19-24}$ Myostatin was initially known as a primary negative regulator of the growth and development of fetal and postnatal skeletal muscle. ${ }^{25,26}$ A variety of approaches to block myostatin function have been developed during the past few years, including i) the creation of a myostatin gene knockout animal model, ii) the use of a myostatin neutralizing antibody, and iii) the delivery of the myostatin propeptide (MPRO) gene via an adenoassociated virus (AAV). These different methods of myostatin blockade have unequivocally shown that the inhibition of myostatin reduces fibrosis and enhances muscle regeneration in both injured and dystrophic murine skeletal muscles. ${ }^{19-24}$ Myostatin directly stimulates the formation of skeletal muscle fibrosis by stimulating muscle fibroblasts, whose excessive activities are responsible for the development of fibrosis in injured muscle. ${ }^{23,27}$ Muscle fibroblasts express the myostatin protein ${ }^{23,27}$ and its receptor, ACVR2B. ${ }^{27}$ Myostatin increases the proliferation and secretion of extracellular matrix products by muscle fibroblasts. ${ }^{23,27}$ These effects may be due to the activation of the canonical TGF- $\beta$ signaling pathway, as well as the $\mathrm{PI3K} / \mathrm{Akt} / \mathrm{mTOR}$ pathway in muscle fibroblasts, as evidenced by increased phosphorylation of SMAD2/3 and $\mathrm{Akt} / \mathrm{mTOR}$, respectively. ${ }^{27}$ Injection of myostatincoated beads into skeletal muscle leads to the formation of fibrosis around the injected beads, which could be reversed with the addition of follistatin, an antagonist of myostatin. ${ }^{27}$ Myostatin and TGF- $\beta 1$ have been observed to reciprocally induce the expression of one another. ${ }^{23,28}$ The blockade of TGF- $\beta 1$ signaling impairs myostatin's biological activity and vice versa, which suggests that TGF- $\beta 1$ acts synergistically with myostatin to induce fibrosis in injured skeletal muscle. ${ }^{23}$

In addition to impairing skeletal muscle healing by promoting fibrosis, myostatin also inhibits myofiber regeneration in mouse models that mimic diseases such as Duchenne muscular dystrophy (DMD) ${ }^{22}$ and amyotrophic lateral sclerosis-associated muscular atrophy, ${ }^{29}$ as well as after experiencing a traumatic injury. ${ }^{20,23}$ Specifically, the diaphragm muscles of mdx mice, an animal model of DMD, were noted to undergo significantly more myofiber damage and less myofiber regeneration when compared with transgenic $\mathrm{mdx}$ mice that also had their myostatin gene knocked out. ${ }^{22}$ Similarly, in two acute muscle injury models, the first where the tibialis anterior muscle was injured by the injection of notexin and the other where the gastrocnemius muscle (GM) was injured via laceration, there was significantly greater regeneration and significantly less fibrosis formation in the injured myostatin knockout mice than the injured wild-type (WT) controls. ${ }^{20,23}$ Given the promising benefits of blocking myostatin in skeletal muscle, a safety trial using MYO-29, a neutralizing antibody of myostatin, was conducted in adult patients with various forms of muscular dystrophy, including Becker muscular dystrophy, facioscapulohumeral dystrophy, and limb-girdle muscular dystrophy. ${ }^{30}$ The results of this trial demonstrated that the pa- tients could tolerate MYO-29 very well when it was administrated systemically. ${ }^{30}$

Research into the development of therapies to antagonize myostatin has led to the discovery of several new functions exhibited by follistatin. Follistatin was originally found to antagonize activin $A$ in reproductive tissues and was also observed to neutralize several other proteins within the TGF- $\beta$ superfamily. ${ }^{31-33}$ Follistatin is also well known as a potent myostatin antagonist in skeletal muscle. $^{34,35}$ Follistatin-overexpressing transgenic mice exhibit a significant increase in muscle mass, much as is seen to occur in myostatin knockout mice. ${ }^{35}$ Several in vivo studies on follistatin have shown that the systemic administration of this agent directly inhibits myostatin and also reduces myostatin-induced muscle wasting. ${ }^{26,34,36}$ Moreover, a single injection of AAV-mediated follistatin into the quadriceps and tibialis anterior muscles, of both young and aged WT C57BL/6J or dystrophic mice, increased the muscles weight, and more interestingly, it also promoted an increase in the weight of noninjected muscles located remotely (eg, triceps muscles). This increase in muscular weight was accompanied by an increase in hind limb grip strength. It is also noteworthy that increased follistatin levels were not detrimental to the reproductive capacity of the treated animals. ${ }^{37}$ Apart from these animal model findings, it has also been reported that follistatin plays a beneficial role in human myoblast transplantation. Human myoblasts-overexpressing follistatin outperformed normal human myoblast controls in both proliferation and differentiation capacities in vitro and regenerated much larger engraftment areas when injected into the tibialis anterior muscles of severe combined immunodeficiency (SCID) mice. ${ }^{38}$ The safety and effectiveness of follistatin treatment have been evaluated in nonhuman primates. ${ }^{39}$ The long-term expression of the AAV-mediated follistatin in the quadriceps muscles of cynomolgus macaque monkeys increased the monkeys' muscle mass and strength without having any deleterious effects on any of their critical organ systems. ${ }^{39}$ This minimal off-target effect makes this molecule a promising potential therapeutic agent to treat muscles injured acutely and injured by degenerative muscle disorders; however, before translating follistatin-based therapies from the bench to the bedside, clear mechanisms of how follistatin promotes muscle regeneration requires extensive investigation.

In this report, we provide in vivo and in vitro data to support the application of follistatin as a potential therapeutic agent to enhance skeletal muscle healing after injury and disease. In addition, we investigated the underlying mechanisms of action that follistatin has on muscle cell regeneration, angiogenesis, and fibrosis formation. Specifically, we show that follistatin-overexpressing transgenic mice undergo more efficient skeletal muscle regeneration while developing less fibrosis after muscle injury (laceration) compared with WT controls. This enhancement of muscle healing in follistatin-overexpressing mice after injury appears to be related, at least in part, to an increase in the myogenic potential of muscle progenitor cells (MPCs), likely due to follistatin's inhibition of myostatin, activin $A$, and TGF- $\beta 1$. Finally, we 
also performed experiments to determine how follistatin affects the expression and downstream signaling of TGF- $\beta 1$ and the expression of a variety of myogenic transcription factors.

\section{Materials and Methods}

\section{Animal Model}

\section{Comparison of Muscle Healing between WT and Follistatin-Overexpressing Mice after Injury}

All animal experiments were approved by the Children's Hospital of Pittsburgh's Institutional Animal Care and Use Committee. We performed partial cross-sectional lacerations on the GMs of 23 male C57BL/6 WT (Jackson Laboratories, Bar Harbor, ME) and 23 male follistatin-overexpressing mice (all mice were 7 to 8 weeks of age) according to a previously published protocol. ${ }^{11-14,17,23}$ The muscles were then harvested at 1 $(n=3), 2(n=8)$, and $4(n=8)$ weeks and at 1.5 years $(n=4)$ after creating the laceration injury. Each of the harvested muscles had the percentage of fibrosis and muscle regeneration quantified, as previously described. ${ }^{23}$ Briefly, after the cryosectioning of these muscles, histologic staining was performed with a Masson's trichrome kit (IMEB Inc., Chicago, IL). The amount of fibrosis formation in each of the muscles was measured by selecting three representative and nonadjacent sections and photographing up to three microscopic fields $(\times 20)$. Images were taken for each section to ensure that the entire muscle section was completely photographed. We then pieced the images together in Adobe Photoshop CS3 (San Jose, CA) and quantified the percentage area of fibrosis using Northern Eclipse software version 6.0 (Empix Imaging Inc., Cheektawaga, NY) by measuring the area of fibrotic tissue along the sites of injury and then dividing this area by the total cross-sectional area of the entire tissue section.

To evaluate skeletal muscle regeneration, we stained sections from each harvested muscle with H\&E. For each sample, three nonconsecutive sections were chosen in each section and images were taken from two to five microscopic fields $(\times 100)$ and then pieced together, as described above, to make sure the entire injured area was covered. The smallest diameters of centronucleated myofibers, which represent newly regenerating muscle fibers, were quantified with Northern Eclipse software. This technique of measuring the smallest diameters of the centronucleated myofibers is a widely used method for evaluating muscle regeneration. ${ }^{22,23,26,37,40,41}$ The diameters of more than 350 nonconsecutive, centronucleated myofibers were measured in each of the GMs. Moreover, the percentages of the regenerating myofibers were also determined in each of the injured muscles at all time points.

In addition, we performed immunohistochemical (IHC) staining to detect myostatin, activin A, collagen type IV, and phosphorylation of SMAD2/3 in each of the injured GMs. We also stained for CD31, which is an endothelial cell marker that we used as an index of neoangiogen- esis in the injured muscles, via IHC staining. The CD31-positive structures were counted using Northern Eclipse software.

\section{Intramuscular Injection of AAV2-MPRO/GFP into WT Mice}

Twenty male C57BL/6J WT mice (8 weeks old; Jackson Laboratories) were used for these experiments. Fifty microliters of AAV serotype 2 (AAV2)-MPRO $\left(2.5 \times 10^{12}\right.$ viral genome $/ \mathrm{mL}$ ) was injected into both $\mathrm{GMs}$ of 10 mice. The same dose of AAV2-GFP was injected into the GMs of 10 additional mice as controls. One month after AAV2 vector injection, both GMs of each mouse were subjected to laceration injury. The mice were sacrificed 4 weeks after creating the laceration injury, and muscle regeneration and fibrosis were measured as described previously for the follistatin-overexpressing and WT mice.

\section{Fluorescence Immunostaining}

Frozen GMs were sectioned at a thickness of $10 \mu \mathrm{m}$, and $\mathrm{IHC}$ analysis was then performed to detect myostatin, activin $A$, collagen type IV, and phosphorylation of SMAD2/3. Tissue sections were fixed in $4 \%$ formalin for 5 minutes followed by two 10-minute washes with PBS. The sections were first incubated with 10\% horse serum (HS; Vector Laboratories, Burlingame, CA) for 1 hour to block nonspecific staining. Goat antimyostatin, activin $A(R \& D$ Systems, Minneapolis, MN), p-SMAD2/3 (Santa Cruz Biotechnology Inc., Santa Cruz, CA) or rabbit anticollagen IV (Meridian, Saco, ME) primary antibody were diluted $1: 100$ in $2 \%$ HS in PBS and incubated on the sections overnight at $4^{\circ} \mathrm{C}$. Sections were then washed three times with PBS and incubated with a secondary antibody, antigoat/rabbit IgG conjugated with biotin (1:200) (Vector Laboratories), for 1 hour at room temperature, followed by a PBS wash. Finally, streptavidin conjugated with Alexa Fluor 555 or 488 (1:500) (Invitrogen, Carlsbad, CA) was applied to each section for an additional hour. DAPI (Sigma, St Louis, MO) was used to counterstain the nuclei. We then quantified the amount of myostatin expression that was present in the injured muscles using Northern Eclipse software, which measures the area and intensity of the detected antibody of interest's signal along the sites of injury. This was then divided by the total cross-sectional area of the tissue to calculate the percentage of the injured muscle tissue that was positive for the detected antibody of interest. The negative controls were stained using the same procedure but without the primary antibody.

To monitor angiogenesis, we first incubated the sections with 10\% HS for 1 hour and then incubated with a rat CD31 primary antibody (BD Biosciences, San Jose, CA) that was diluted $1: 150$ in $2 \%$ HS in PBS. This preparation was incubated for 1 hour at room temperature. The sections were then washed three times with PBS and incubated for 30 minutes with the secondary antibody, rabbit anti-rat IgG conjugated with Alexa Fluor 555 (Invitrogen). Finally, DAPI was used to counterstain the nuclei. 


\section{MPC Isolation and Transplantation into Skeletal Muscle}

Using a modified preplate technique, ${ }^{42,43}$ we isolated a fraction of MPCs with properties of low adhesion to collagen and long-term proliferation. Briefly, we determined the sex of the neonatal mice by anatomically sexing them and then isolated five populations of WT MPCs from five male neonatal C57BL/6J mice and also isolated seven populations of follistatin-overexpressing MPCs from seven male neonatal follistatin-overexpressing mice. These cells were expanded in proliferation medium consisting of Dulbecco's modified Eagle's medium (Invitrogen), 10\% HS (Invitrogen), 10\% fetal bovine serum (Invitrogen), 1\% penicillin-streptomycin (Invitrogen), and $0.5 \%$ chicken embryo extract (Accurate Chemical \& Scientific Corporation, Westbury, NY).

After the MPC populations were expanded in vitro, MPCs were injected into the GMs of female $\mathrm{mdx} / \mathrm{SCID}$ mice. These mice were generated by crossbreeding mdx (C57BL/ 10ScSn-Dmdmdx) and SCID (C57BL/6J-prkdcscid/SzJ) mice (Jackson Laboratory) at our institution's animal facility. Approximately $3 \times 10^{5}$ cells from each cell population were transplanted into the GMs of four female mdx/SCID mice. All mdx/SCID mice were sacrificed 2 weeks after transplantation. The recipient GMs from these mice were harvested at this time, snap-frozen, and cryosectioned at a later date at a thickness of $10 \mu \mathrm{m}$ per section.

Each section was immunostained for dystrophin with a rabbit anti-mouse dystrophin antibody to monitor the number of dystrophin-positive myofibers formed by the donor MPCs. The tissue sections were first fixed in 5\% formalin for 5 minutes, followed by two 10-minute washes with PBS. The sections were blocked with $10 \%$ donkey serum for 1 hour and then incubated overnight at $4^{\circ} \mathrm{C}$ with a rabbit dystrophin primary antibody (Abcam, Cambridge, MA) that was diluted 1:500 in 5\% donkey serum in PBS. The following day, these sections were washed three times with PBS and incubated with the secondary antibody donkey anti-rabbit IgG conjugated with Alexa Fluor 594 (Invitrogen). Images (×200) of the sections representing the largest dystrophin-positive engraftment areas in up to 10 microscopic fields were taken for each sample and then spliced together to cover the entire engraftment area. Dystrophin-positive myofibers were then counted to assess the efficiency of cell transplantation in the skeletal muscle of the mdx/SCID mice.

\section{Flow Cytometry}

To characterize WT and follistatin-overexpressing MPC populations, we used flow cytometry using antibodies specific for CD34 and Sca-1 on both WT and follistatin-overexpressing MPCs to analyze the percentage of stem cells in the MPC populations as previously described. ${ }^{42,43}$ Briefly, cultured cells were trypsinized, centrifuged, and washed twice with PBS. We subsequently resuspended our cell pellets, blocked them with $10 \%$ mouse serum (Sigma) for 10 minutes on ice, and then applied rat anti-mouse monoclonal conjugated antibodies (CD34 phycoerythrin, Sca-1 allophycocyanin; BD Biosci- ences) and incubated on ice for 30 minutes. After this incubation period, we excluded nonviable cells by adding 7-aminoactinomycin D (BD Biosciences) to each sample. Cells were then evaluated with a FACS Caliber flow cytometer (Becton Dickinson) and analyzed with CellQuest software (Becton Dickinson).

\section{Cell Culture}

A C2C12 myoblast cell line (ATCC, Manassas, VA) was seeded overnight onto collagen-coated 12-well plates in normal growth medium (10\% fetal bovine serum and $1 \%$ penicillin-streptomycin in Dulbecco's modified Eagle's medium). The next day, this medium was replaced with low-serum medium ( $2 \% \mathrm{HS}$ and $1 \%$ penicillin-streptomycin in Dulbecco's modified Eagle's medium), which promotes the myogenic differentiation of myoblasts, supplemented with different combinations of the recombinant proteins outlined below. The medium and recombinant proteins were changed every 48 hours.

In the first set of experiments, C2C12 myoblasts were stimulated with follistatin recombinant protein (Sigma-Aldrich, St. Louis, MO) and cultured for up to 4 days. The effect of follistatin on myogenic differentiation and the expression of MyoD, Myf5, myogenin, and myostatin were examined by myosin heavy chain (MyHC) immunostaining and Western blot analysis.

In the second set of experiments, C2C12 myoblasts were stimulated with a combination of follistatin, activin A, and myostatin. The myogenic differentiation of these cells was then evaluated via MyHC immunostaining by calculating the fusion index (ie, the ratio of nuclei in myotubes to all nuclei) according to a previously published protocol. $^{23}$ Images of five representative microscopic fields were taken of each well from the 12-well plates.

In the final set of experiments, we incubated C2C12 myoblasts with varying concentrations of the recombinant proteins follistatin and TGF- $\beta 1$. The cells were then either cultured for 4 days and stained for $\mathrm{MyHC}$ to check their myogenic differentiation capacity or cultured 16 hours before collecting the cells to analyze them for TGF- $\beta 1$, SMAD2, and p-SMAD2 expression. In the latter set of cells, cell lysates were collected in preparation for Western blot analysis.

\section{Western Blot}

Cultured cells were lysed with T-PER Tissue Protein Extraction Reagent with the addition of protease inhibitors (Pierce, Rockford, IL). Equal amounts of cellular protein were loaded into each well and separated by $10 \%$ SDSPAGE. Nitrocellulose membrane blotting was then performed under standard conditions. For immunoblotting, we used the following primary antibodies: mouse anti- $\beta$-actin IgG (1:8000) (Sigma-Aldrich), rabbit antiTGF- $\beta 1$ IgG (1:1000) (Abcam Inc.), goat anti-Myf-5 (Santa Cruz Biotechnology Inc.), mouse anti-MyoD and myogenin IgGs (1:250) (BD Biosciences), and goat anti-SMAD2 and p-SMAD2 IgGs (Cell Signaling Technology, Danvers, MA). 
A
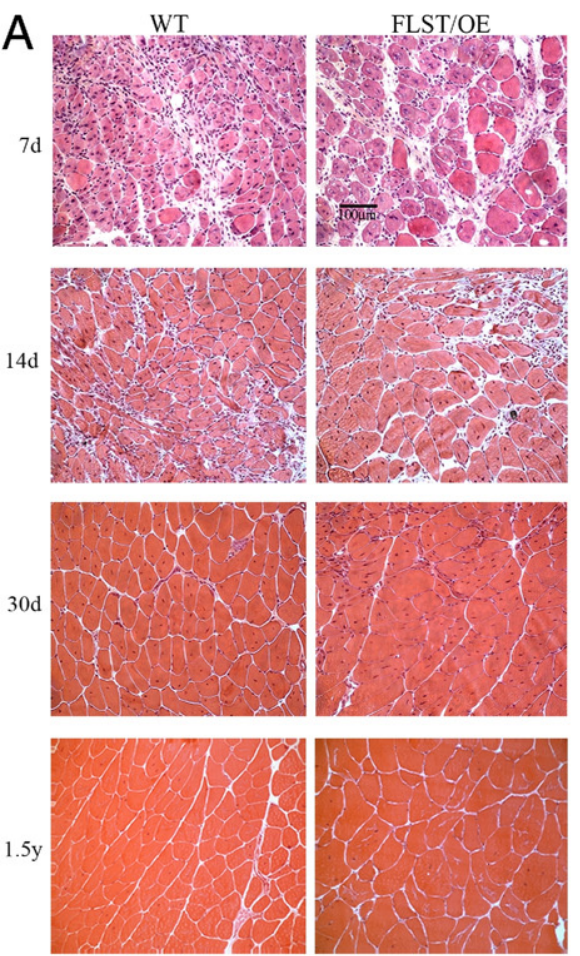

B

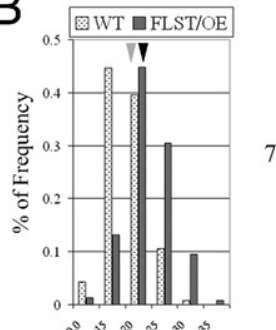

$7 d$
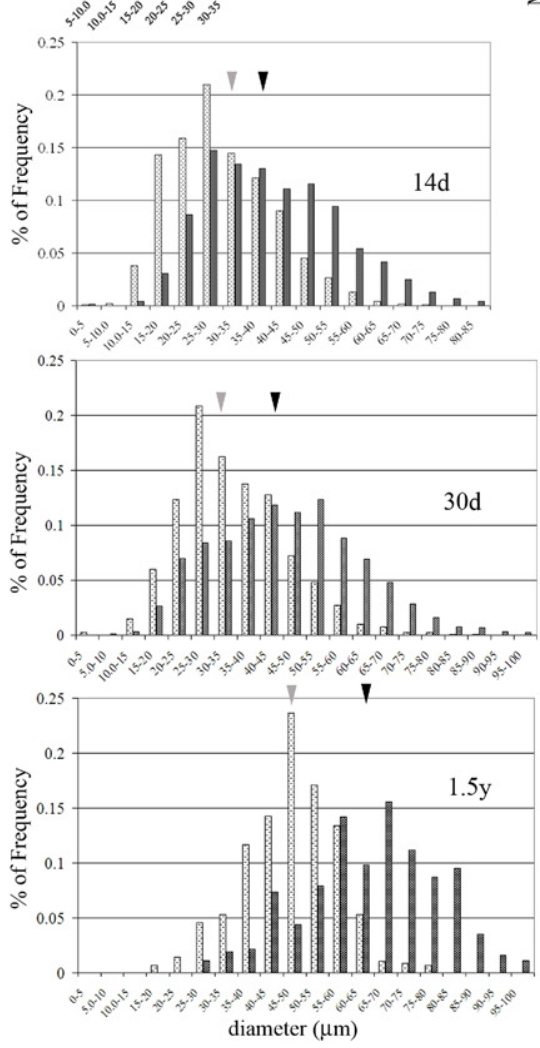

C

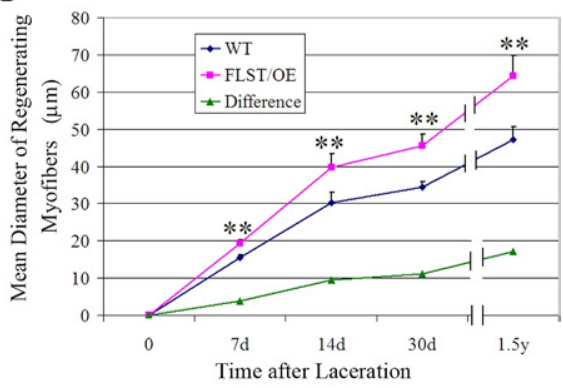

Figure 1. Injured follistatin-overexpressing (FLST/OE) skeletal muscles showed accelerated regeneration compared with their WT counterparts. A: H\&E staining of cross-sections of injured WT and FLST/OE skeletal muscle at 7, 14, and 30 days and 1.5 years after laceration injury. The myofibers and nuclei stained red and black respectively. Original magnification, $\times 200$. Regenerating myofibers are characterized by centralized nuclei. Black scale bar represents 100 $\mu \mathrm{m}$. B: Distribution of diameters of regenerating myofibers in WT and FLST/OE skeletal muscle 7 $(n=3), 14(n=8)$, and $30(n=8)$ days and 1.5 years $(n=4)$ after injury. Gray bars represent myofibers from WT mice, whereas black bars represent myofibers from FLST/OE mice. Moreover, the gray arrowheads indicate mean diameters of regenerating fibers in WT muscle, whereas black arrowheads indicate mean diameters of regenerating fibers in FLST/OE muscle. C: Regenerating myofiber diameter quantifications. The smallest diameters of more than 300 nonadjacent myofibers per muscle were measured using Northern Eclipse software. The mean diameters of regenerating fibers were shown to increase in both WT and FLST/OE muscles over time after injury; however, the mean diameters of the FLST/OE fibers were significantly greater at all time points $\left({ }^{*} P<0.05,{ }^{* *} P<0.01\right)$.

\section{Real-Time PCR}

C2C12 cells were grown in media containing varying amounts of follistatin at $0,200,400$, and $1000 \mathrm{ng} / \mathrm{mL}$ that was added every 48 hours and collected at 1 and 4 days after plating using Trizol (Invitrogen). RNA was precipitated, processed, and purified using the Qiagen RNeasy kit. RNA was DNase treated and quantitated on a spectrophotometer. To normalize variation among samples, a standard amount of $10 \mathrm{ng}$ of RNA was used. Promega Go-Taqll-step real-time quantitative PCR (A6010) was used to run all samples. Predesigned SYBR primer sets were obtained from Qiagen for both myostatin and glyceraldehyde-3-phosphate dehydrogenase. The ABI $7900 \mathrm{HT}$ fast real-time PCR system was used to obtain $\mathrm{C}_{\mathrm{T}}$ values of the genes of interest. $\mathrm{C}_{\mathrm{T}}$ values were calculated using ABI SDS 2.3 software (Applied Biosystems by Life Technologies, Carlsbad, CA). Samples were normalized to glyceraldehyde-3-phosphate dehydrogenase expression, and the $\Delta \Delta \mathrm{C}_{\mathrm{T}}$ method of data analysis was used. The formula for fold change is $2^{-}\left(\Delta \Delta C_{T}\right)$ and is used to show differences among treatments. Gene ex- pression levels were examined and normalized to untreated control cultures.

\section{Statistical Analysis}

All data are reported as mean \pm SD or mean \pm SEM, and data analyses have been performed with Student's $t$-test for comparisons between two groups and with a one-way analysis of variance for comparisons among three or more groups (SPSS Inc., Chicago, IL). For all statistically significant differences observed after performing oneway analysis of variance, the appropriate multiple comparison tests were used to perform a post hoc analysis. Statistical significance was considered at $P<0.05$.

\section{Results}

\section{Improved Healing in Follistatin-Overexpressing Skeletal Muscle}

To investigate whether follistatin could promote skeletal muscle healing after injury, we used a follistatin- 
A
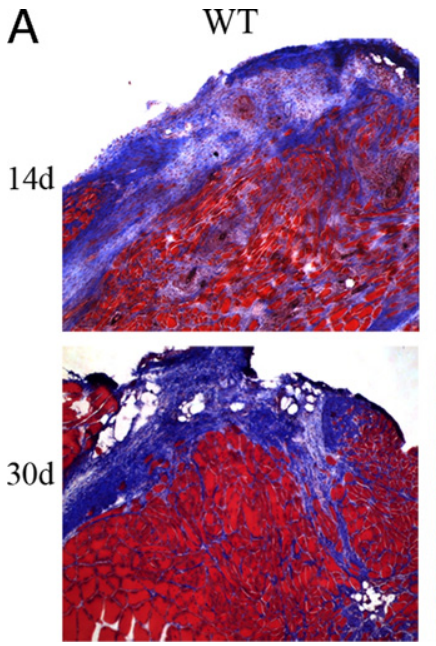
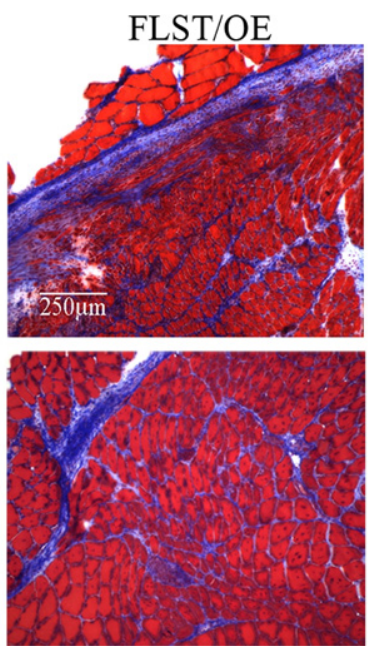

B

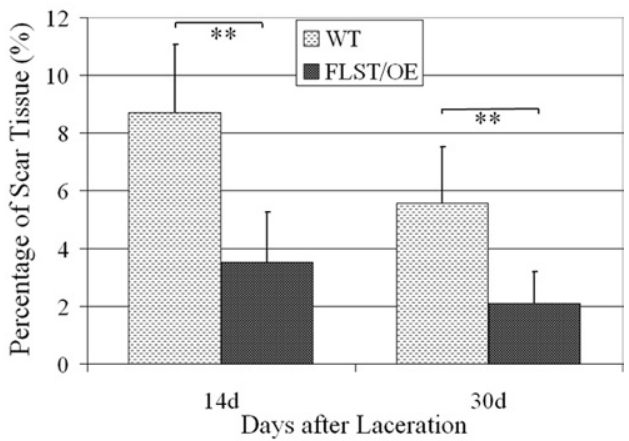

Figure 2. Fibrosis formation in the injured follistatin-overexpressing (FLST/OE) muscle was reduced when compared with the injured WT muscle. Masson's trichrome staining was performed on sections of injured FLST/OE and WT muscle (myofibers in red; fibrosis in blue). A: Representative images of injured FLST/OE and WT muscle at $14(n=8)$ and $30(n=8)$ days after injury. Original magnification, $\times 100$. There was significantly less fibrosis observed in the injured FLST/OE muscles than the WT muscles. B: Injured FLST/OE muscles developed significantly less fibrosis than did injured WT muscles $(* * P<0.01)$.

overexpressing transgenic mouse model to examine whether skeletal muscle healing after injury would differ from WT controls. After laceration, the GMs, from the WT and follistatin-overexpressing mice, were both observed to undergo regeneration as confirmed by the presence of centronucleated myofibers at the site of injury (Figure 1A). The myofiber diameters were determined 7 days after laceration and ranged in size from $5 \mu \mathrm{m}$ to $35 \mu \mathrm{m}$ (Figure 1B). Over time, the diameters of the regenerating myofibers increased in size, with the mean diameter of the regenerating myofibers in the follistatin-overexpressing muscle being significantly larger than those observed in the WT muscle. The mean diameters of the regenerating follistatin-overexpressing myofibers, as measured at the postlaceration time points of 7,14 , and 30 days and 1.5 years, were larger by approximately 25.3\% (19.37 $\pm 0.80 \mu \mathrm{m}$ versus $15.46 \pm 0.81 \mu \mathrm{m} ; P<0.01), 31.6 \%$ (39.77 \pm 3.69 $\mu \mathrm{m}$ versus $30.22 \pm 2.75 \mu \mathrm{m} ; P<0.01), 32.5 \%(45.55 \pm$ $3.03 \mu \mathrm{m}$ versus $34.38 \pm 1.56 \mu \mathrm{m} ; P<0.01)$, and $36.3 \%(64.36 \pm 5.40 \mu \mathrm{m}$ versus $47.22 \pm 3.49 \mu \mathrm{m} ; P<$ 0.01 ), respectively, than those of the WT mice (Figure 1C). The absolute differences in the mean diameters of the regenerating myofibers between the WT and follistatin-overexpressing mice were also shown to increase (green curve in Figure 1C). Accordingly, the injured muscles of follistatin-overexpressing mice compared with the WT animals contained a higher percentage of larger myofibers at each of the postinjury time points tested. For example, at 7 days $51 \%$ of the regenerating WT myofibers were larger than $15 \mu \mathrm{m}$, and $86 \%$ of the regenerating follistatin-overexpressing myofibers were larger than $15 \mu \mathrm{m}$. At 14 days, $45 \%$ of the WT regenerating myofibers were larger than $30 \mu \mathrm{m}$, whereas $73 \%$ of the follistatin-overexpressing regenerating myofibers fell into the 30 - to $85-\mu \mathrm{m}$ diameter group. At 30 days, $40 \%$ of the regenerating WT myofibers were larger than $35 \mu \mathrm{m}$, whereas $73 \%$ of the regenerating follistatin-overexpressing myofibers were larger than $35 \mu \mathrm{m}$ (Figure 1B). Nevertheless, no significant difference was found in the percentage of regenerating myofibers between the injured follistatin-overexpressing muscles and the WT control muscles (see Supplemental Figure S1 at http://ajp.amjpathol.org).

In addition to the differences in myofiber regeneration, we observed significant differences in the deposition of collagenous connective tissue after injury between the regenerating WT and follistatin-overexpressing muscles. Specifically, at 14 days after laceration, fibrosis developed extensively in the WT muscles but was relatively limited in the follistatin-overexpressing muscles (Figure 2A). The amounts of fibrosis quantified at 14 days after injury within the WT and follistatinoverexpressing GMs, respectively, were $8.71 \% \pm$ $2.36 \%$ and $3.54 \% \pm 1.71 \%(P<0.01)$ (Figure $2 \mathrm{~B}$ ). Compared with these values obtained at 14 days, our quantification analysis showed a reduction in fibrosis at 30 days in the injured WT and follistatin-overexpressing GMs (Figure 2A). Despite this, the relative amounts of fibrosis formation in the WT GMs continued to be significantly greater than the follistatin-overexpressing GMs $(5.57 \% \pm 1.94 \%$ versus $2.10 \% \pm 1.10 \% ; P<$ 0.01 ) (Figure 2B). Fibrosis in the injured GMs of the WT and follistatin-overexpressing mice was reduced at 1.5 years after injury (data not shown).

It has been reported that follistatin inhibits myostatin by directly binding to the molecule. ${ }^{34,35}$ Notably, we found a reduction of the myostatin protein in the injured muscles of follistatin-overexpressing mice. This became apparent 2 weeks after injury, when we noted that the follistatin-overexpressing muscles showed less myostatin signal than the WT muscles, as indicated by immunostaining (Figure 3A). Collagen IV (green) stains the basal lamina, which outlines the myofibers, and the myostatin protein (red) is seen to be mostly localized in the cytoplasm of the regenerating, centronucleated fibers (Figure 3A, arrows); however, some of the myostatin-positive regenerating myofibers lacked a com- 
A MSTN+Collagen IV+Nuclei

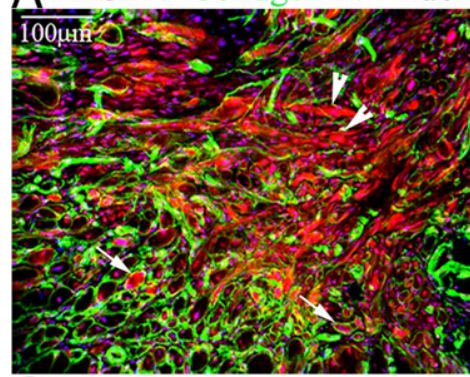

C CD31

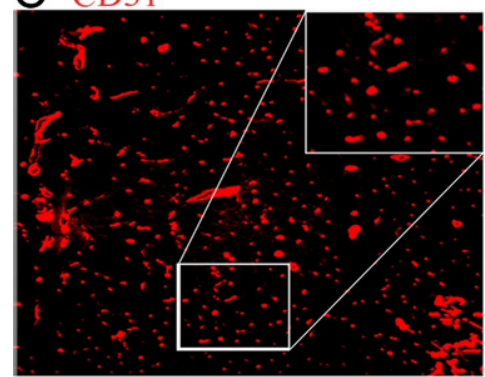

WT
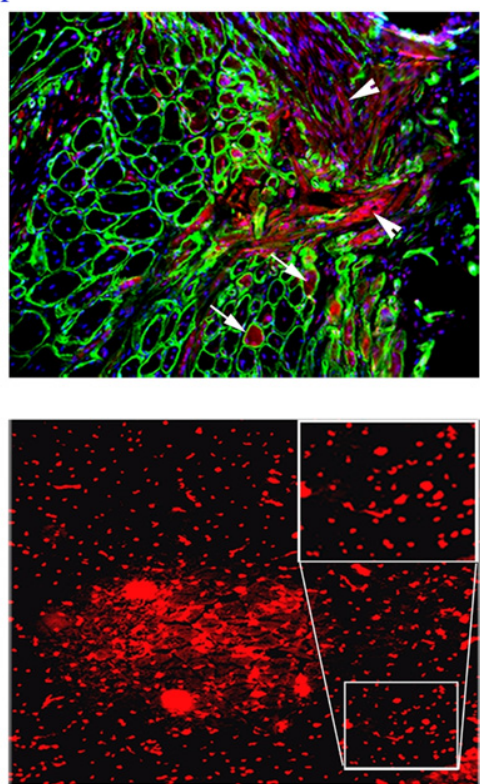

FLST/OE
B

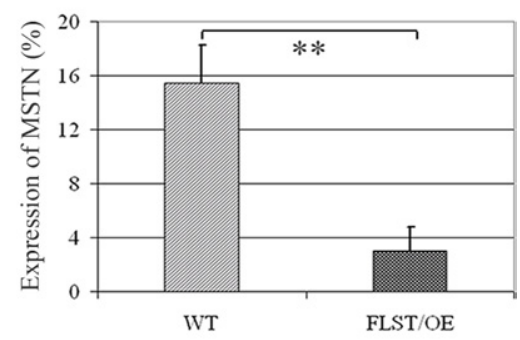

D

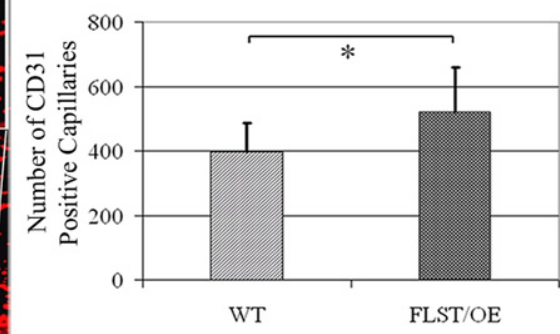

Figure 3. Decreased myostatin (MSTN) expression and increased angiogenesis in injured follistatin-overexpressing (FLST/OE) skeletal muscles. A: IHC analysis was performed to detect MSTN (red) and collagen type IV (green) expression in injured WT and FLST/OE muscle. Collagen type IV was used to highlight the basal lamina of myofibers, including necrotic, intact, and regenerating myofibers. MSTN-positive signals were seen within some of the regenerating myofibers surrounded by the basal lamina (arrows) and some expression outside the basal lamina (arrowheads). Original magnification, $\times 200$. Injured FLST/OE muscles contained less MSTN staining than did injured WT muscles. B: When we measured the relative MSTN positive signals and areas, we found that there was significantly more MSTN expression detected in the injured WT muscles than in injured FLST/OE muscles. C: CD31, an endothelial cell marker, was used to stain capillary-like structures in the injured muscles. Original magnification, $\times 200$. D: There were a significantly greater number of $\mathrm{CD} 31^{+}$signals present in the injured FLST/OE muscles than in the injured WT muscles $(n=8)\left({ }^{*} P<0.05,{ }^{* * *} P<0.01\right)$.

pletely intact basal lamina (Figure 3A, arrowheads). When measuring the area and intensity of the myostatin signal in the injured muscles, we found that myostatin in the injured follistatin-overexpressing muscles was significantly lower than that observed in the WT controls (Figure 3B). Similarly, 2 weeks after injury, the activin $A$ immunostaining signal in the injured follistatin-overexpressing muscles was also decreased when compared with the WT controls (see Supplemental Figure S2 at http://ajp.amjpathol.org). Furthermore, we detected a trend that phosphorylation levels of SMAD2/3 in the injured muscles of follistatin-overexpressing mice were lower than that observed in the WT controls (see Supplemental Figure S3 at http://ajp.amjpathol.org).

It has been found that follistatin stimulates angiogenesis both in vitro and in vivo ${ }^{44}$ and that the presence of increased angiogenesis has been reported to be involved with a reduction in the formation of fibrosis. ${ }^{45}$ These findings have led us to examine neovascularization in the injured follistatin-overexpressing and WT muscles. We assessed the vascularity of injured follistatin-overexpressing and WT muscles at 30 days after laceration and observed that the follistatin-overexpressing muscles had a significantly larger number of $\mathrm{CD} 1^{+}$capillary-like structures along the zone of injury compared with their WT counterparts (Figure 3, C and D). This finding indicates that increased vascularity may be, at least partially, responsible for the improved muscle healing observed in follistatin-overexpressing mice.

\section{Comparison of WT and Follistatin- Overexpressing MPCs}

To elucidate why follistatin-overexpressing muscles show a better regenerative capacity after injury than WT muscles, we compared MPCs isolated from follistatin-overexpressing skeletal muscle to WT MPCs. We used flow cytometry and immunocytochemistry to analyze the expression of stem cell (Sca-1, CD34) and myogenic (desmin) markers and also determined the proliferation and myogenic differentiation capacities of these two cell populations. The heterogeneous profile of the stem cell marker expression is apparent from the histograms in Figure 4A. Cell populations from both the follistatin-overexpressing and WT groups expressed these surface markers $\left(\mathrm{Sca}-1^{+}\right.$and $\mathrm{CD} 34^{+}, \mathrm{Sca}_{-} 1^{+}$only, and CD34 ${ }^{+}$ only), although at different levels. Compared with the WT MPC populations, the follistatin-overexpressing populations contained a significantly larger percentage of cells that were positive for Sca-1 (Figure 4, A and B). The representative images of the flow cytometry dot plots showed that one of the follistatin-overexpressing MPC populations and one of the WT MPC populations contained $46.5 \%$ and $24 \%$ Sca- $1^{+}$cells, respectively (Figure $4 \mathrm{C})$. In the low serum medium, both follistatin-overexpressing and WT MPCs were capable of fusing into multinucleated myotubes as demonstrated by $\mathrm{MyHC}$ and DAPI staining (Figure 4D). The percentage of desminpositive cells and proliferation and myogenic differentiation capacities were also compared between the follista- 
A
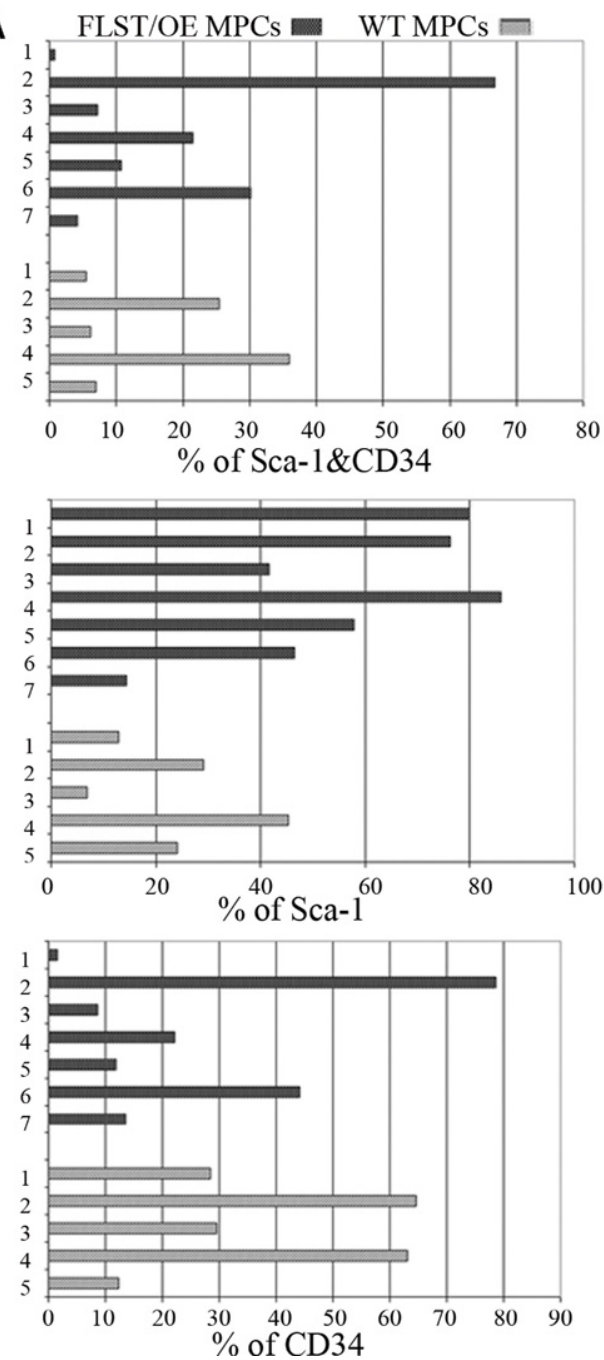

B

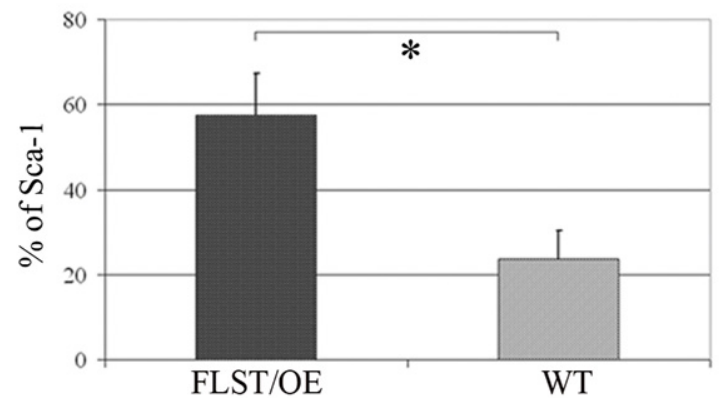

Isotype control
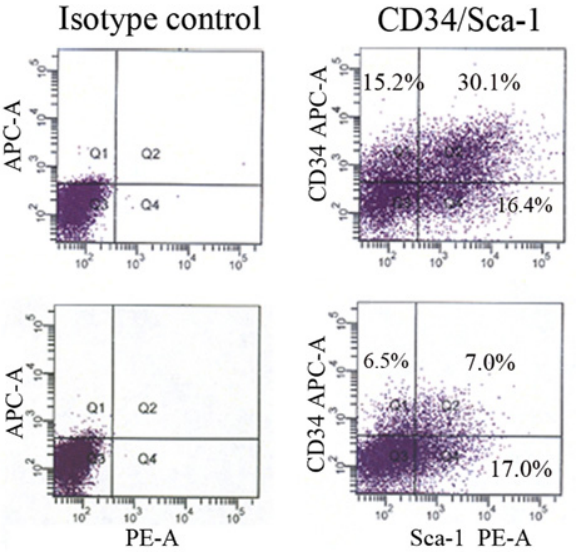

D

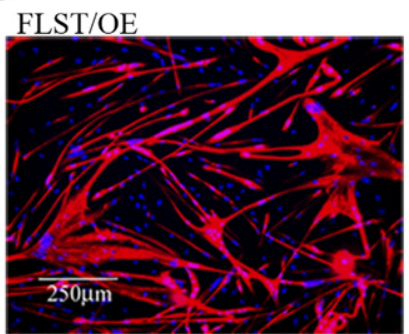

WT

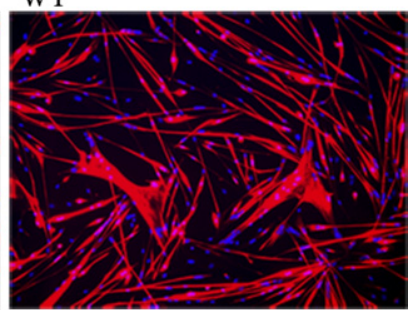

Figure 4. Characterization of MPCs. Seven follistatin-overexpressing (FLST/OE) and five WT MPC populations were examined for Sca-1 expression, CD34 expression, and in vitro myogenic differentiation. A: Histograms showing wild variability in the percentages of Sca- $1^{+}$and CD34 ${ }^{+}, \mathrm{Sca}_{-} 1^{+}$, and CD34 ${ }^{+}$expressing cells among the MPC populations. B: Quantitation revealed a significant increase in the Sca- $1^{+}$fraction in the FLST/OE MPC populations compared with the WT MPC populations. C: Images on the left are isotype controls; images on the right are representative images of a flow cytometry dot plot showing that FLST/OE MPC populations consist of a larger proportion of Sca- $1^{+}$cells than the WT MPC populations (46.5\% versus 24\%). APC-A indicates allophycocyanin-area; PE-A, phycoerythrin area. D: Both FLST/OE and WT MPC populations underwent myogenic differentiation as labeled by MyHC (red) and DAPI (blue). Original magnification, $\times 100$.

tin-overexpressing and WT MPC populations; however, because of high variability, no significant differences were observed (data not shown).

MPCs are a population of primary, long-term proliferating cells that regenerate skeletal muscle more efficiently than myoblasts when transplanted into the muscles of dystrophic mice. ${ }^{43,46}$ We posited that follistatin-overexpressing MPCs would likely be superior to WT MPCs at regenerating skeletal muscle because of our finding that injured follistatin-overexpressing muscles underwent better muscle regeneration than did the WT control muscles. Using the preplate technique, ${ }^{43,46}$ we isolated MPCs from both WT and follistatin-overexpressing mice and compared their ability to regenerate skeletal muscle by injecting them into the GMs of mdx/SCID mice. Quantification of the number of dystrophin-positive myofibers was performed to evaluate the cell transplantation efficiency. Notwithstanding, a high degree of variability was observed in the WT and follistatin-overexpressing MPCs' abilities to regenerate myofibers in vivo (Figure 5A). Only two of five of the WT MPC populations produced more than 200 dystrophin-positive myofibers, whereas six of seven of the follistatin-overexpressing cell populations regenerated more than 200 myofibers. Specifically, whereas the WT MPC population with the greatest potential to generate dystrophin-positive myofibers was able to regenerate 400 fibers, four of the seven follistatin-overexpressing populations regenerated between 500 and 1398 fibers (Figure 5A). Moreover, all of the follistatin-overexpressing MPC populations produced more fibers than the mean fiber number (eg, 195.6 myofibers) produced by the WT MPC populations (Figure 5, A and B). Overall, the follistatin-overexpressing MPCs $(n=7)$ produced significantly larger muscle engraftments than did the WT cells $(n=5)(592.8 \pm 154.9$ versus $195.6 \pm 65.4 ; P=0.023$; Student's $t$-test) (Figure $5 \mathrm{~B})$. Two representative dystro- 
A

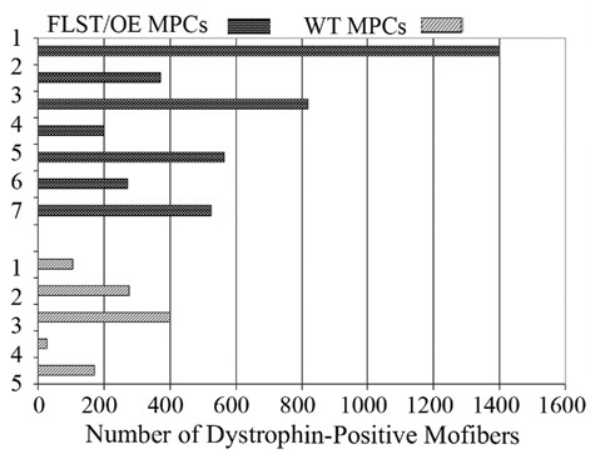

C

Number of Dystrophin-Positive Mofibers
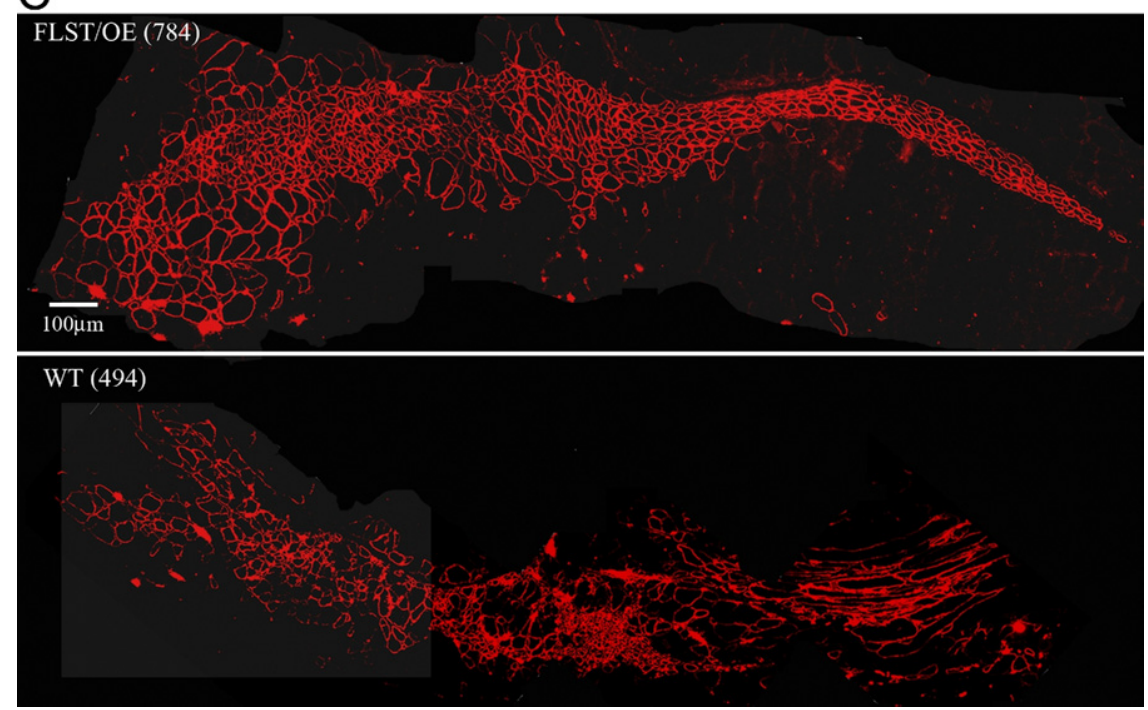

B

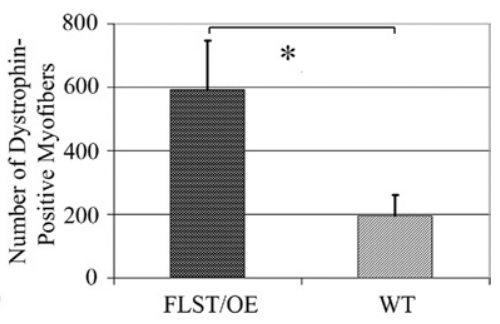
OE MPCs) regenerated skeletal muscle more efficiently than WT MPCs, when transplanted into the GMs of $\mathrm{mdx} / \mathrm{SCID}$ mice. A: Quantitation of engraftment in terms of the number of dystrophin-positive fibers regenerated by the FLST/OE and WT MPC populations. B: The overall mean \pm SEM number of dystrophin-positive myofibers was significantly greater for the FLST/OE MPCs $(592.8 \pm 154.9 ; n=7$ FLST/OE MPC populations; four muscles per population) than for the WT MPC populations (195.6 \pm 65.4 $n=5$ WT MPC populations; four muscles per population; ${ }^{* * *} P=0.023$, Student's $t$-test). C: Representative engraftments showed that the transplanted MPCs regenerated dystrophin-positive myofibers (red) within dystrophic muscle FLST/OE MPCs produced more dystrophin-positive myofibers than did WT MPCs $\left({ }^{*} P<0.05,{ }^{*} P<\right.$ 0.01). Original magnification, $\times 200$. phin-positive engraftments derived from the follistatinoverexpressing and WT MPCs (784 versus 494 dystrophin-positive myofibers, respectively) are shown in Figure 5C.

\section{Interaction between Follistatin and TGF- $\beta$ Superfamily Members}

Recombinant myostatin protein inhibited the myogenic differentiation ability of $\mathrm{C} 2 \mathrm{C} 12$ myoblasts in vitro, and our results indicate that follistatin can neutralize exogenous myostatin, thereby allowing the C2C12 myoblasts to undergo myogenic differentiation (Figure 6A). We further showed that, much as is the case with myostatin's effect on myoblasts, activin A can also significantly inhibit the myogenic differentiation capacity of C2C12 cells (Figure 6B). We also demonstrated that follistatin can significantly attenuate the myogenic inhibitory effect that activin A has on C2C12 myoblast's capacity to differentiate into myotubes (Figure 6C).

Myogenic differentiation, in particular, involves sequential steps where myoblasts initially retract from the cell cycle and thereafter differentiate and fuse into multinucleated myotubes. TGF- $\beta 1$ inhibits myoblast differentiation, and although muscle cells are able to withdraw from the cell cycle when cultured in fusion induction medium supplemented with TGF- $\beta 1$, these cells fail to fuse into myotubes as is evidenced by the lack of muscle creatine kinase and nicotinic acetylcholine receptor expression. ${ }^{47}$ Here, we have shown that TGF- $\beta 1$ inhibits the myogenic differentiation of $\mathrm{C} 2 \mathrm{C} 12$ myoblasts in fusion induction medium. In contrast to the extensive myotube formation observed in the control $\mathrm{C} 2 \mathrm{C} 12$ cells not treated with TGF- $\beta 1$, there were only a few small myotubes interspersed among numerous nuclei (blue) in cell cultures treated with TGF- $\beta 1$ (Figure 7A). In cell cultures treated with both TGF- $\beta 1$ and increasing concentrations of follistatin, follistatin was observed to counteract TGF- $\beta 1$ 's inhibition of the C2C12 myoblast's myogenic capacity (Figure 7A). The fusion indices indicated that follistatin significantly increased the myogenic differentiation capacity of the C2C12 myoblasts and that TGF- $\beta 1$ significantly decreased their myogenic differentiation capacity. Moreover, follistatin prevented TGF- $\beta 1$ from inhibiting myogenesis and partially restored the myogenic differentiation capacity of the $\mathrm{C} 2 \mathrm{C} 12$ myoblasts exposed to TGF- $\beta 1$ (Figure 7B). Follow-up experiments demonstrated that follistatin also decreased TGF- $\beta 1$ expression by the $\mathrm{C} 2 \mathrm{C} 12$ myoblasts with and without the exogenous application of TGF- $\beta 1$ (Figure 7 C). In addition, the TGF- $\beta 1$ signaling pathway relies on the activation of an intracellular SMAD signaling cascade, and our results indicated that follistatin blocks this pathway 
A

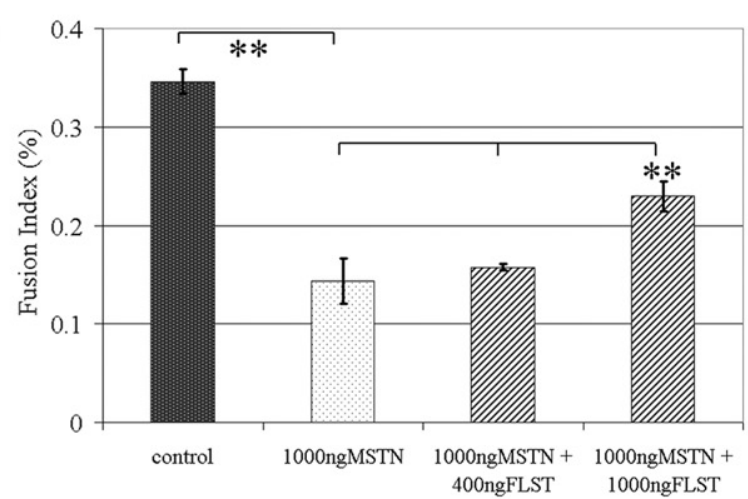

B

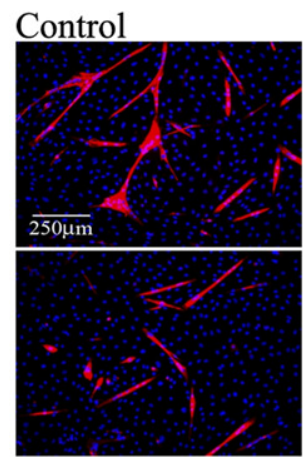

$200 \mathrm{ng} / \mathrm{ml}$
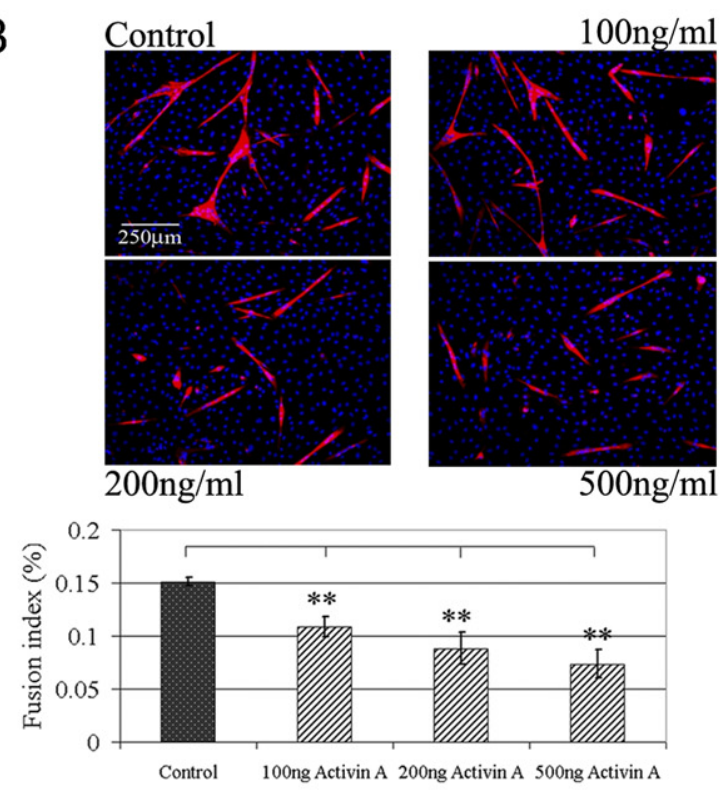

C

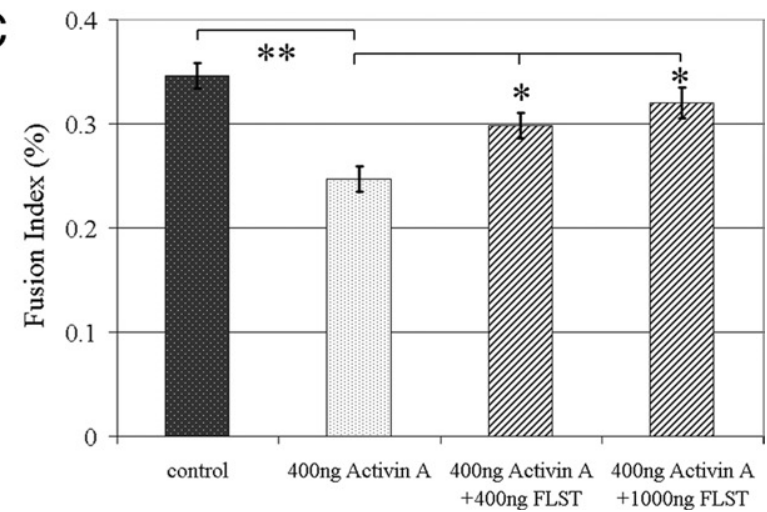

Figure 6. Interactions between follistatin (FLST) and myostatin (MSTN) and FLST and activin A. A: As indicated by the fusion index (the ratio of nuclei in myotubes to total nuclei), MSTN significantly inhibited C2C12 myoblast differentiation, but FLST counteracted MSTN and attenuated its inhibition of cellular differentiation. B: Without intervention, $\mathrm{C} 2 \mathrm{C} 12$ myoblasts underwent myogenic differentiation in low serum medium as evidenced with $\mathrm{MyHC}$ (red) and DAPI (blue). Activin A significantly reduced muscle cell differentiation and the formation of myotubes in cell culture. Original magnification, $\times 100$. C: FLST could neutralize the inhibitory effect of activin A on myoblast differentiation as shown by FLST induced-restoration of differentiation $\left(n=3 ;{ }^{*} P<0.05,{ }^{* * *} P<0.01\right)$.

by reducing the expression and phosphorylation of SMAD2 (Figure 7D).

Our group has previously shown that follistatin stimulates C2C12 myoblasts to undergo myogenic differentiation ${ }^{23}$ and significantly increases the fusion index of the cells when compared with untreated controls and does so in a dose-dependent fashion. ${ }^{23}$ In our complementary experiments from the current study, during the early stages of myogenic differentiation (day 1), when there is no detectable myotube formation, there is a notable increase in the expressions of MyoD and Myf5 in the $\mathrm{C} 2 \mathrm{C} 12$ cells treated with follistatin when compared with untreated cells. During

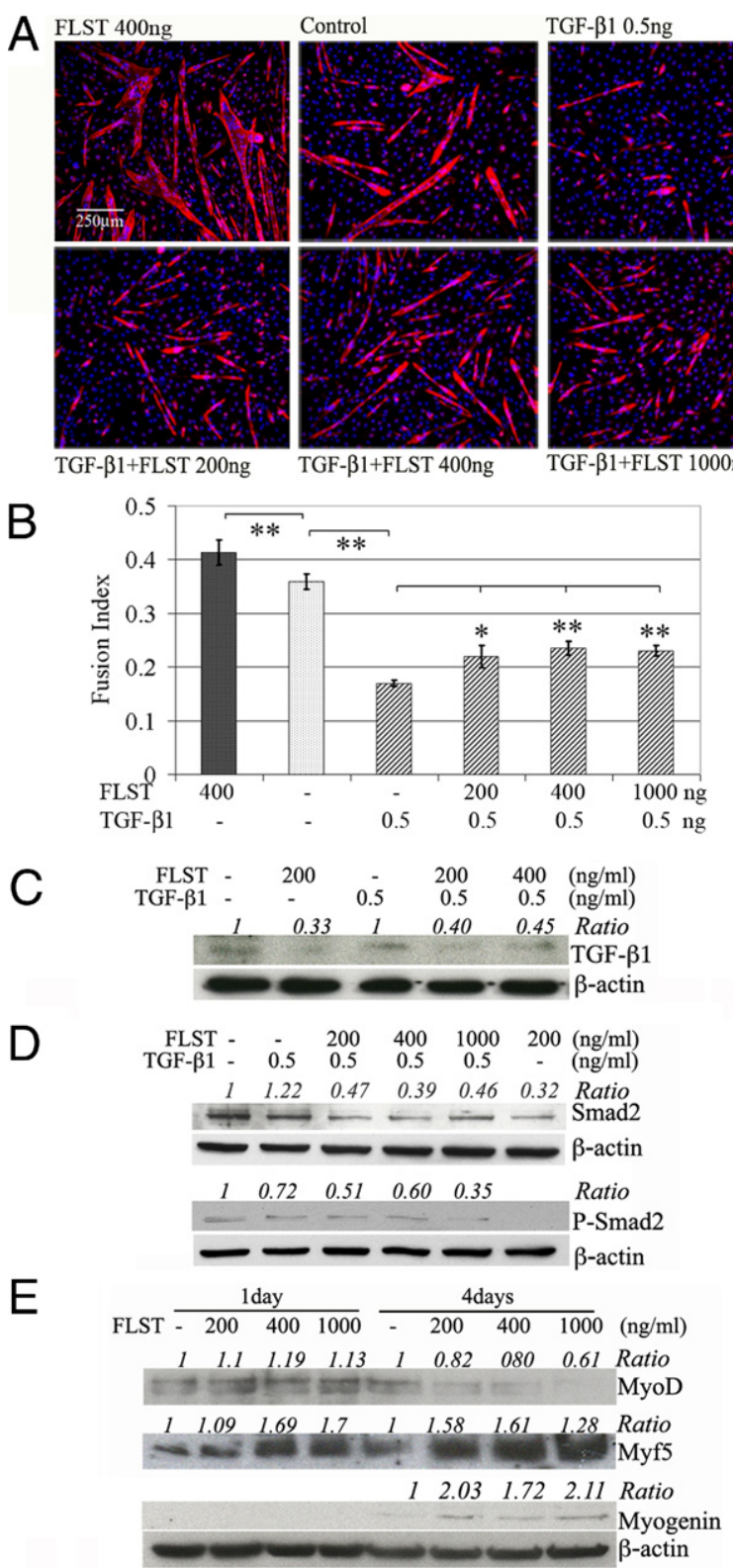

Figure 7. Follistatin (FLST) neutralized TGF- $\beta 1$ 's activity on C2C12 myoblasts A: Exemplary pictures of differentiation of $\mathrm{C} 2 \mathrm{C} 12$ myoblasts treated by FLST alone, TGF- $\beta 1$, and combinations of FLST and TGF- $\beta 1$. Original magnification, $\times 100$. Myotubes were visualized with MyHC (red) and DAPI (nuclei, blue) B: Our quantitative results showed that TGF- $\beta 1$ significantly inhibited myogenic differentiation of $\mathrm{C} 2 \mathrm{C} 12$ myoblasts. FLST was able to reverse TGF- $\beta 1$-inhibited myogenic differentiation $(n=3)$. C: Western blot results showed that FLST decreased TGF- $\beta 1$ expression in C2C12 myoblasts with or without the presence of exogenous TGF- $\beta 1$. D: FLST also reduced the phosphorylation of SMAD2. E: FLST stimulated the expressions of the myogenic regulatory factors, MyoD, Myf5, and myogenin by myoblasts; the quantification of the Western blots was indicated as normalized ratio of proteins of interest to $\beta$-actin, whereas controls were referred to as $1\left({ }^{*} P<0.05,{ }^{* * *} P<0.01\right)$ 

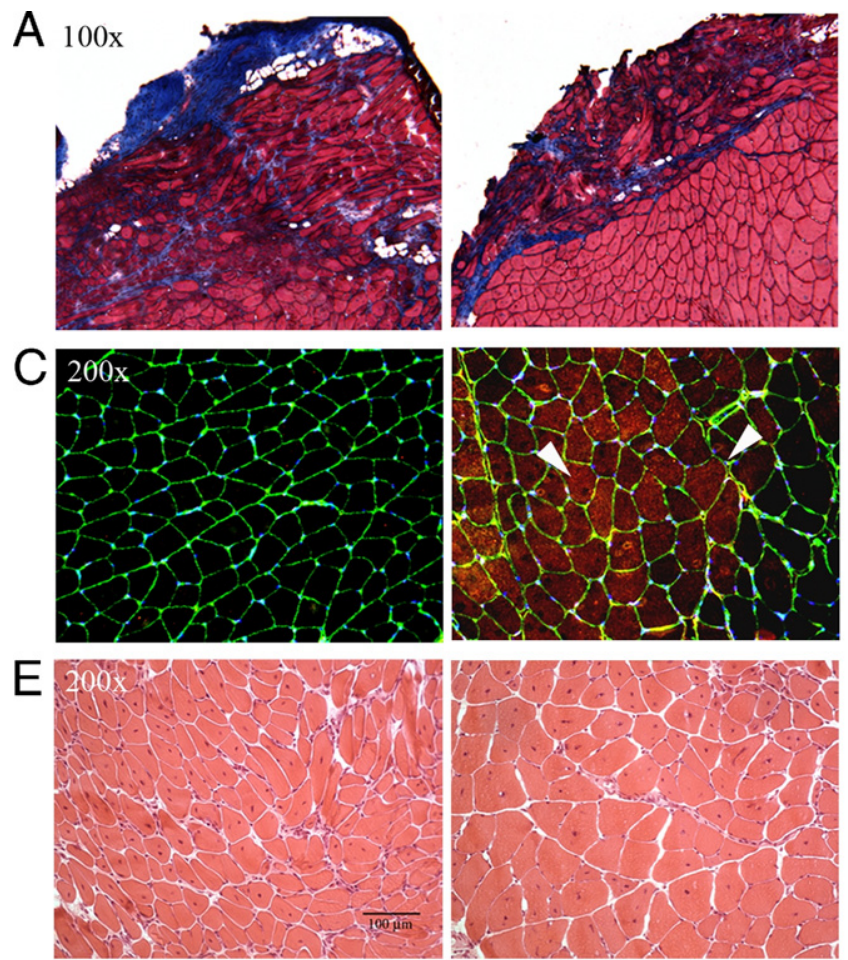
Control

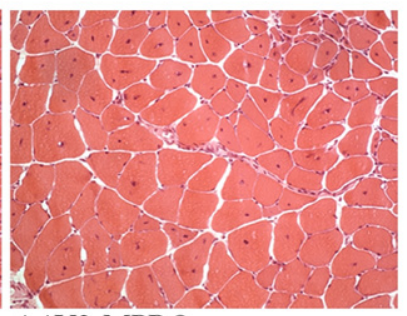

AAV2-MPRO

$\mathrm{G}$

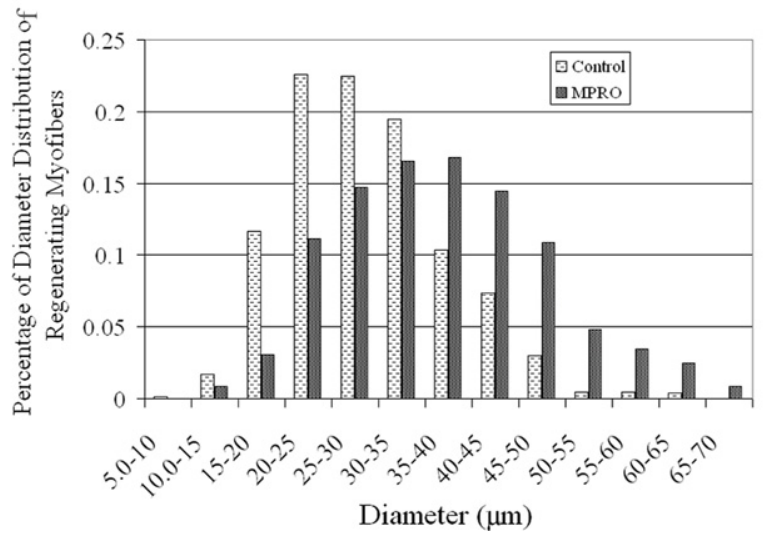

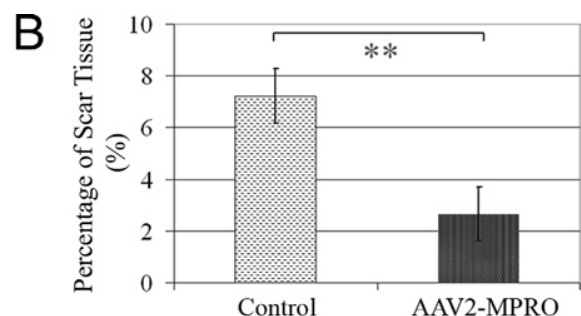

D

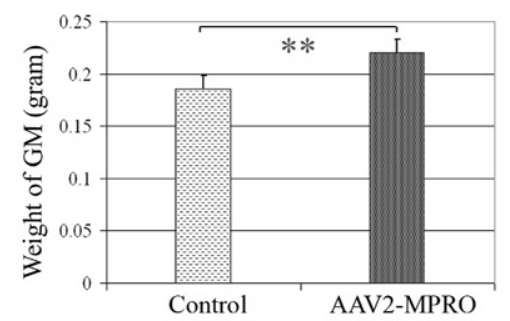

$\mathrm{F}$

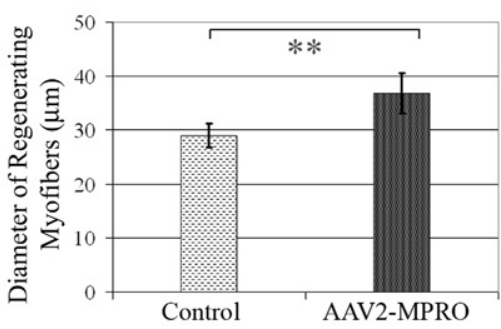

Figure 8. AAV2-MPRO improves skeletal muscle healing at 4 weeks after injury. A: Masson's trichrome staining shows that fibrotic tissue (blue) exists at the muscle injury site. B: Fibrosis in the AAV2-MPRO-treated injured muscles was significantly less than the untreated control. Original magnification, $\times 200$. C: Collagen IV (green) and MPRO (red) doubleimmunostaining shows a strong MPRO signal in the cytoplasm of the fibers of AAV2-MPRO transduced muscle. D: AAV2MPRO transduced GMs gained significantly more weight than the GM controls. E: H\&E staining revealed muscle hypertrophy in the AAV2-MPRO-treated injured muscles. F: A significant increase in the average diameter of the regenerating myofibers was observed in the AAV2-MPRO injected muscles when compared with the controls ( ${ }^{* *} P<0.01$ ). Original magnification, $\times 100$. G: Frequency histograms show the distribution of regenerating myofibers in the AAV-MPRO-treated and control muscles. Scale bar $=100 \mu \mathrm{m}$. the late stages of differentiation (day 4), in which the formation of myotubes is extensive, C2C12 cells exposed to follistatin augment their expression of myogenin and maintain elevated expression levels of Myf-5 compared with the untreated controls (Figure 7E).

\section{AAV2-Delivered MPRO Inhibits MSTN Activity in Vivo}

To make our results described above more therapeutically relevant, we performed an experiment to examine whether blocking MSTN using an AAV2-MPRO vector could improve the healing of injured skeletal muscle. Either an AAV2-MPRO or AAV2-GFP control vector was injected into the GMs of adult C57BL/6J mice 1 month before injuring the muscles. The mice were then sacrificed 4 weeks after GM laceration injury. Similar to what we observed in the follistatin-overexpressing muscles, the injured GMs overexpressing MPRO exhibited better healing than the AAV2-GFP transduced controls. Masson's trichrome staining showed extensive fibrosis infiltration in the injured WT skeletal muscle, whereas the injured AAV2-MPRO transduced muscle formed significantly less fibrotic tissue (Figure $8, \mathrm{~A}$ and B) $(7.2 \% \pm$ $1.1 \%$ versus $2.6 \% \pm 1.0 \% ; P<0.01)$. The MPRO gene was stably expressed in the transduced muscles injected with the AAV-MPRO vector (Figure $8 \mathrm{C}$ ). The weights of the AAV2-MPRO transduced GMs were also significantly greater than the WT counterpart muscles (Figure 8D). Moreover, we observed larger regenerating myofibers in the injured muscles transduced with AAV2-MPRO than in the injured WT muscles (Figure 8E). The mean diameter of the regenerating myofibers in the GMs overexpressing MPRO was significantly increased (by 26.7\%) over what was observed in the nontransduced GMs $(36.8 \pm 3.8 \mu \mathrm{m}$ versus $29.0 \pm 2.2 \mu \mathrm{m} ; P<0.01$ ) (Figure $8 \mathrm{~F}$ ). Corre- 
spondingly, the distribution of diameters of the regenerating myofibers revealed that $78.0 \%$ of the regenerating myofibers in the control muscles had diameters smaller than $35 \mu \mathrm{m}$ when compared with $46.3 \%$ found in the AAV2-MPRO transduced muscles. In contrast, $53.7 \%$ of the regenerating myofibers in the injured AAV2-MPRO transduced muscles had a diameter in the range of 35 to $70 \mu \mathrm{m}$ (Figure 8G).

\section{Discussion}

In this study, we showed that the skeletal muscle healing of follistatin-overexpressing mice is accelerated when compared with the skeletal muscle of WT mice. Specifically, the mean diameter of the regenerating myofibers in the injured follistatin-overexpressing muscles remained significantly larger than their WT counterparts. Moreover, fibrosis formation was significantly lower in the injured follistatin-overexpressing muscles than the injured WT muscles. These results are comparable to those that we previously observed in the injured GMs of myostatin knockout mice. ${ }^{23}$ There are several possible explanations for follistatin's augmentation, which include i) decreasing levels of myostatin, activin $\mathrm{A}$, and the phosphorylated SMAD2/3; ii) promoting vascularity in the injured muscles; and iii) enhancing the ability of MPCs to regenerate the injured muscle fibers. This last explanation was confirmed by in vitro results, which showed that follistatin could promote myoblast differentiation by blocking myostatin, activin $A$, and TGF- $\beta 1$, all negative regulators of muscle regeneration, and also by augmenting the expression of the myogenic transcription factors MyoD, Myf5, and Myogenin. Although we discuss these events individually, we highlight that they are not mutually exclusive of one another but rather illustrate how follistatin can synergistically promote healing through each of these processes.

\section{Mechanisms Involved in the Reduction of Fibrosis Formation in Injured Follistatin- Overexpressing Muscle}

TGF- $\beta 1$ expression in injured skeletal muscle is time dependent, peaking at 3 to 5 days and then again at 10 to 14 days after injury. 5,6,48 The latter event appears to be associated with the formation of fibrosis and ineffective muscle regeneration. ${ }^{5}$ When the second peak of TGF- $\beta 1$ expression is blocked with the administration of an antifibrotic agent at 14 days after injury, it leads to histologic and physiologic improvements of the injured muscles. ${ }^{5,10-}$ 14,16,17 Coincidently, our in vivo studies showed significant decreases in myostatin immunostaining among the injured follistatin-overexpressing GMs 14 days after injury. Given our in vitro results that follistatin does not down-regulate the mRNA expression of myostatin in C2C12 myoblasts (see Supplemental Figure S4 at http://ajp.amjpathol.org), the decreased myostatin levels observed in the injured follistatin-overexpressing muscle may not be the result of a decrease in myostatin transcription. It has been shown that follistatin can be released into the blood circulation ${ }^{26,37}$; therefore, the reduction in the myostatin signal in the injured follistatin-overexpressing muscle, partially caused by excessive circulating follistatin and follistatin within the muscle's extracellular matrix, can sequester myostatin and prevent it from binding to the injured muscle tissue. Moreover, some small regenerating myofibers, without intact basal lamina, were found in the current study to be strongly myostatin positive in the injured WT and follistatin-overexpressing GMs, which was similar to our previous findings. ${ }^{23} \mathrm{Li}$ et al reported that some regenerating myofibers appeared to degrade and transform into myofibroblasts, which aggravated fibrosis formation in the injured skeletal muscles. ${ }^{5}$ If this is the case, these myostatin-positive, basal lamina-deficient regenerating fibers may represent a transitional state of regenerating myofibers that are undergoing the differentiation process into myofibroblasts. A decrease in the amount of myostatin at the injury site likely accounts for the reduction in fibrosis observed in the injured follistatin-overexpressing muscles given the fact that myostatin directly stimulates fibrosis in skeletal muscle $\mathrm{e}^{20,23,27}$ and the lack of myostatin would also attenuate the profibrotic effects of TGF- $\beta 1 .{ }^{23}$ In addition, we showed that follistatin downregulates the expression of TGF- $\beta 1$ and counteracts its activity in vitro. Myostatin, TGF- $\beta 1$, and activin $A$ all belong to the TGF- $\beta$ superfamily and all signal through the TGF- $\beta /$ SMAD2/3 signaling pathway. Our data indicate that there is an overall decrease in the phosphorylation level of SMAD2/3 in the injured follistatin-overexpressing muscle when compared with the WT controls. Although we do not have direct evidence showing that follistatin also reduces fibrosis through the inhibition of TGF- $\beta 1$ and activin A, our results appear to demonstrate that follistatin decreases the TGF$\beta$-like signaling that occurs through the SMAD2/3 pathway, thereby attenuating the inhibitory effect of this pathway on skeletal muscle healing.

We also showed that significantly more CD $31^{+}$capillary-like structures appeared in the injured follistatinoverexpressing muscles than in the injured WT controls; however, more evidence is required to validate the vascular functionality of these $\mathrm{CD} 31^{+}$structures. It is noteworthy to point out that angiogenesis correlates with an increase in skeletal and cardiac muscle regeneration and a reduction in fibrosis. ${ }^{45,49-52}$ In the present study there is insufficient evidence to indicate whether follistatin directly stimulates angiogenesis in injured skeletal muscle; nevertheless, accumulating evidence in other studies suggests that follistatin expression can be positively correlated with angiogenesis by a variety of different cells and tissues. ${ }^{42,53-55}$ Follistatin expression is up-regulated by activated endothelial cells but down-regulated on the cell's withdrawal from the cell cycle. ${ }^{55}$ Follistatin promotes the proliferation of several types of endothelial cells, including human umbilical vein endothelial cells and bovine aortic endothelial cells. ${ }^{55}$ Follistatin alone moderately stimulates angiogenesis in the rabbit cornea, and its angiogenic effect can be greatly reinforced when 
combined with basic fibroblast growth factor. ${ }^{55}$ In addition, follistatin was recently found to function as a binding protein of angiogenin, which is known to induce angiogenesis via the activation of endothelial and smooth muscle cells. ${ }^{53}$ Follistatin and angiogenin colocalize in the nuclei of HeLa cells, suggesting that the follistatin and angiogenin interaction may play an important role in angiogenin-induced angiogenesis. ${ }^{53} \mathrm{~A}$ "Ioss of function" experiment validated that the follistatin isoform 288 is essential for promoting angiogenesis during mouse embryo formation. ${ }^{56}$ Importantly, activin $A$ and TGF- $\beta 1$ have been shown to inhibit the growth and activation of a spectrum of vascular endothelial cells ${ }^{55,57}$; therefore, it is possible that follistatin partially promotes angiogenesis by antagonizing TGF- $\beta$ 's inhibition of endothelial cells. Nevertheless, the effects that follistatin and TGF- $\beta$ have on skeletal muscle vascular endothelial cells remain to be elucidated. Revascularization in injured skeletal muscle is a critical event during muscle regeneration. The speed and quality of tissue repair are directly correlated with the degree of vascular ingrowth into the muscle injury site, which provides an adequate supply of oxygen and nutrients to promote efficient regeneration. ${ }^{58,59}$ The regeneration of multinucleated myofibers in injured muscles will be impaired if there is an insufficient supply of oxygen due to an inadequate supply of energy resulting from insufficient aerobic metabolism. ${ }^{58,60}$ Given the stimulatory effects that follistatin exerts on endothelial cells, it is reasonable to speculate that follistatin may be able to promote the growth of new capillaries to increase the blood supply to the injury site. The increase in blood supply would further accelerate the resorption of scar tissue and increase muscle regeneration.

\section{Cellular Mechanism by which Follistatin Promotes Skeletal Muscle Regeneration after Injury}

The development of skeletal muscle during embryogenesis and its regeneration after trauma, or in the setting of skeletal muscle disease, largely occur through the differentiation of muscle cells into myofibers. ${ }^{61-63}$ Satellite cells in adult skeletal muscle can be found within a niche between the basal lamina and sarcolemma of the myofibers, forming a pool of quiescent myogenic progenitor cells. ${ }^{64}$ In response to muscle trauma and during disease processes, these cells are activated to reenter the cell cycle, migrate from the basal lamina to the zone of injury, and undergo asymmetric divisions. A preponderance of daughter cells are committed to differentiate and fuse into multinucleated myofibers, whereas a small portion of self-renewing cells replenish the reservoir of satellite cells by reentering a quiescent state.

Myostatin inhibits satellite cell self-renewal by downregulating their $\mathrm{G} 1$ to $\mathrm{S}$ progression within the cell cycle retaining the satellite cells in a quiescent state. ${ }^{65,66} \mathrm{In}$ versely, myostatin knockout skeletal muscle possesses more satellite cells than their WT counterparts, likely re- sulting from an increase in proliferation and a delay in myogenic differentiation by the adult myostatin knockout satellite cells. ${ }^{65}$ On the basis of this information, we sought to determine the impact that follistatin would have on the regenerative capacity of MPCs. MPCs are a heterogeneous population consisting of myoblasts, satellite cells, and stem cells. We injected MPCs isolated from both follistatin-overexpressing and WT skeletal muscle of mice into the GMs of $\mathrm{mdx} / \mathrm{SCID}$ mice to determine their regeneration efficiency. We found that overall, the follistatin-overexpressing MPC populations regenerated a greater numbers of dystrophin-positive myofibers when compared with the WT MPCs; however, not all of the follistatin-overexpressing MPC populations outperformed their WT counterparts. Variations in regard to the regenerative capacity of both cell types was readily apparent and is a common phenomenon observed collectively when myoblasts, satellite cells, or muscle stem cells are transplanted intramuscularly. ${ }^{43,46,67}$ Specifically, dystrophin-positive myofibers regenerated by the follistatin-overexpressing MPC populations varied from 200 to 1398 fibers, whereas those produced by the WT MPC populations varied from 27 to 400 fibers. The increase in the regenerative capacity of the follistatin-overexpressing MPC populations probably partially accounts for the better regeneration observed in the injured follistatin-overexpressing muscles than was seen in the WT muscles. These findings may help researchers to genetically engineer an optimal cell population for cell-based therapies to treat DMD, a lethal, sex-linked, recessive, muscle-wasting disease that stems from a variety of different mutations of the dystrophin gene. ${ }^{68,69}$ For instance, the transplantation of muscle cells carrying a follistatin transgene into the dystrophic muscle of a DMD patient may enhance the success of cell transplantation compared with that of unengineered MPCs. ${ }^{70}$

We also investigated whether the cell surface marker profile, proliferation rate, and myogenic differentiation capacity of the MPCs could highlight the mechanism by which these cells display a higher muscle regenerative potential in vivo. We found that the MPC populations isolated from both types of mice exhibited a broad heterogeneity of cell surface markers, proliferation rates, and myogenic capacities in vitro; however, despite this heterogeneity, the follistatin-overexpressing MPC populations contained a significantly larger percentage of Sca- $1^{+}$cells than the WT controls. It has been reported that among male muscle-derived stem cell populations, a higher percentage of Sca- $1^{+}$cells in the cell population appeared to positively correlate with a higher regenerative capacity when transplanted into dystrophic mdx mouse skeletal muscle; however, this is not the case for female muscle-derived stem cells. ${ }^{67}$ These findings are consistent with our current findings showing that all of the cells for these studies were isolated from male mice and the follistatin-overexpressing MPC populations used in the current study had a higher percentage of Sca- $1^{+}$cells and showed a better regenerative capacity than the WT cells. 


\section{Molecular Mechanisms by which Follistatin Promotes Myogenesis: Interaction between Follistatin and TGF- $\beta$ s}

The overexpression of follistatin probably has a more profound effect on muscle growth than solely blocking myostatin. As stated above, we found that the differentiation of myoblasts in vitro is inhibited by myostatin, activin $A$, and TGF- $\beta 1$. Each of these factors appears to be inhibited by follistatin; as a result, myoblast differentiation capacity can be restored. Although it has already been shown that follistatin directly antagonizes both myostatin and activin $A$, further investigation is required to determine whether follistatin inhibits TGF- $\beta 1$ directly or indirectly. Moreover, evidence is emerging that activin A may be one of the key growth factors that function in tandem with myostatin to limit muscle growth. ${ }^{41,71}$ The follistatin I mutant, which does not bind activin A effectively, promotes muscle growth to a lesser extent than WT follistatin. Furthermore, unlike WT follistatin, the mutant follistatin fails to induce an increase in the muscle mass of myostatin knockout mice. ${ }^{71}$ It has been recently reported that activin A knockout mice exhibit significant size increases in both their pectoralis and triceps muscles, which provides genetic evidence that activin A may be one of the key growth factors that function in tandem with myostatin to limit muscle growth. ${ }^{41}$ In this study, our results have shown that that follistatin inhibits not only myostatin but also activin A and TGF- $\beta 1$ in $\mathrm{C} 2 \mathrm{C} 12$ myoblast, which may partially explain why follistatin exerts a more striking effect in promoting muscle regeneration in both injured and dystrophic muscle.

There is some evidence, from previously published reports, that also indicates that follistatin's effect on muscle growth is not exclusively linked to blocking the effects of myostatin. First, follistatin-overexpressing mice display even greater skeletal muscle mass than do myostatin knockout mice, suggesting that follistatin's effect on skeletal muscle may result from the ablation of other negative regulators of muscle growth besides myostatin. ${ }^{35}$ Second, Lee et al have also reported that the effect that follistatin has on skeletal muscle does not result solely from the inhibition of myostatin activity. Their findings demonstrated that the overexpression of follistatin led to further increases in the muscle mass of myostatin knockout mice when compared with myostatin knockout mice controls alone. ${ }^{72}$ Third, blocking the activin type IIB receptor causes further increases in the skeletal muscle mass of myostatin knockout mice, suggesting that other growth factors can limit muscle growth via the activin type IIB receptor as does myostatin. ${ }^{40}$ These results implicate the existence of other molecules that could be involved in the observed beneficial effects that follistatin has on muscle growth.

\section{Skeletal Muscle Injury Comparisons between Myostatin Knockout and Follistatin- Overexpressing Mice}

We have previously examined how the loss of myostatin benefits injured skeletal muscle using the same lacera- tion injury model as in the current study. ${ }^{23}$ When retrospectively comparing the current results with those collected from the myostatin knockout mice, we found that the mean diameter of the regenerating myofibers in the follistatin-overexpressing mice was $32.50 \%$ greater than in the WT mice 4 weeks after injury compared with a $21.22 \%$ increase over the WT controls seen in the myostatin knockout mice. Interestingly, there is not much difference in the formation of fibrosis between injured follistatin-overexpressing and myostatin knockout muscle. Although injured follistatin-overexpressing muscle shows more significant reductions in fibrosis formation than injured myostatin knockout muscle $(59.36 \%$ verus $25.00 \%) 2$ weeks after laceration, at 4 weeks after injury, these reductions in fibrosis were inconsequential between the two groups (66.70\% verus $62.30 \%$ ) (see Supplemental Table S1 at http://ajp.amjpathol.org). Similar reductions in fibrosis in injured myostatin knockout and follistatin-overexpressing muscle suggest that the inhibition of myostatin may largely account for the decrease observed in fibrosis in the injured follistatin-overexpressing muscles.

Myostatin knockout MPCs can regenerate significantly more myofibers than WT control MPCs when intramuscularly transplanted into $\mathrm{mdx} / \mathrm{SCID}$ mice. ${ }^{23}$ When follistatinoverexpressing, WT, and myostatin knockout progenitor cells were injected, in parallel, into the skeletal muscle of $\mathrm{mdx} / \mathrm{SCID}$ mice, the follistatin-overexpressing MPCs regenerated three times as many dystrophin-positive myofibers as the WT MPCs (592.8 \pm 154.9 versus $195.6 \pm$ 65.4), whereas the myostatin knockout MPCs showed about a 1.5-fold increase over the WT MPCs (518.1 \pm 117.6 versus $195.6 \pm 65.4$ ) (Figure $5, A$ and $B$; see also Supplemental Figure S5 and Supplemental Table S1 at http://ajp.amjpathol.org). Four of seven (57\%) of the follistatin-overexpressing MPC populations regenerated more than 500 fibers; in contrast, only two of five (40\%) of the myostatin knockout MPC populations did so (Figure 5A; see also Supplemental Figure S5 at http:// ajp.amjpathol.org).

Apart from the results collected from the myostatin knockout and follistatin-overexpressing mice, we further demonstrated that AAV2-mediated MPRO gene therapy improved muscle healing in WT skeletal muscle by inhibiting myostatin. This finding suggests that inhibiting myostatin is applicable for the treatment of injured muscles and myopathic disorders. Taken together, follistatinbased therapies may represent a more effective therapeutic strategy over others that only antagonize myostatin. Moreover, because follistatin generally promotes muscle hypertrophy without targeting specific defective genes (eg, dystrophin, DMD), follistatin renders itself as a potential universal therapeutic reagent to treat a board spectrum of muscle diseases, especially the muscular dystrophies, which lack a clear pathogenic gene defect, such as facioscapulohumeral muscular dystrophy. Furthermore, follistatin exhibited no unusual adverse effects on the reproductive capacity of mice. ${ }^{37}$ Although additional studies are required on primates to warrant follistatin's feasibility for clinical translation, its use stands to be 
potentially beneficial for the treatment of a variety of skeletal muscle injuries and disorders.

\section{Acknowledgments}

We thank Dr. Se-Jin Lee (Johns Hopkins University) for kindly providing the follistatin-overexpressing breeder mice, Dr. Xiao Xiao for the AAV2 vectors, Lynne Bauer for maintaining and breeding the mdx/SCID mice, myostatin knockout mice, and follistatin-overexpressing mice, and James $H$. Cummins for his editorial assistance in the preparation of the manuscript.

\section{References}

1. Border WA, Noble NA: Transforming growth factor beta in tissue fibrosis. N Engl J Med 1994, 331:1286-1292

2. Lijnen PJ, Petrov VV, Fagard $\mathrm{RH}$ : Induction of cardiac fibrosis by transforming growth factor-beta(1). Mol Genet Metab 2000, 71:418-435

3. Waltenberger J, Lundin L, Oberg K, Wilander E, Miyazono K, Heldin $\mathrm{CH}$, Funa $\mathrm{K}$ : Involvement of transforming growth factor-beta in the formation of fibrotic lesions in carcinoid heart disease. Am J Pathol 1993, 142:71-78

4. Yamamoto T, Noble NA, Miller DE, Border WA: Sustained expression of TGF-beta 1 underlies development of progressive kidney fibrosis. Kidney Int 1994, 45:916-927

5. Li Y, Foster W, Deasy BM, Chan Y, Prisk V, Tang Y, Cummins J, Huard $\mathrm{J}$ : Transforming growth factor-beta1 induces the differentiation of myogenic cells into fibrotic cells in injured skeletal muscle: a key event in muscle fibrogenesis. Am J Pathol 2004, 164:1007-1019

6. Li Y, Huard J: Differentiation of muscle-derived cells into myofibroblasts in injured skeletal muscle. Am J Pathol 2002, 161:895-907

7. Bernasconi P, Torchiana E, Confalonieri P, Brugnoni R, Barresi R, Mora M, Cornelio F, Morandi L, Mantegazza R: Expression of transforming growth factor-beta 1 in dystrophic patient muscles correlates with fibrosis. Pathogenetic role of a fibrogenic cytokine. J Clin Invest 1995, 96:1137-1144

8. Gosselin LE, Williams JE, Deering M, Brazeau D, Koury S, Martinez DA: Localization and early time course of TGF-beta 1 mRNA expression in dystrophic muscle. Muscle Nerve 2004, 30:645-653

9. Cohn RD, van Erp C, Habashi JP, Soleimani AA, Klein EC, Lisi MT, Gamradt M, ap Rhys CM, Holm TM, Loeys BL, Ramirez F, Judge DP Ward CW, Dietz HC: Angiotensin II type 1 receptor blockade attenuates TGF-beta-induced failure of muscle regeneration in multiple myopathic states. Nat Med 2007, 13:204-210

10. Chan YS, Li Y, Foster W, Fu FH, Huard J: The use of suramin, an antifibrotic agent, to improve muscle recovery after strain injury. Am J Sports Med 2005, 33:43-51

11. Chan YS, Li Y, Foster W, Horaguchi T, Somogyi G, Fu FH, Huard J: Antifibrotic effects of suramin in injured skeletal muscle after laceration. J Appl Physiol 2003, 95:771-780

12. Foster W, Li Y, Usas A, Somogyi G, Huard J: Gamma interferon as an antifibrosis agent in skeletal muscle. J Orthop Res 2003, 21:798-804

13. Sato K, Li Y, Foster W, Fukushima K, Badlani N, Adachi N, Usas A, Fu $\mathrm{FH}$, Huard J: Improvement of muscle healing through enhancement of muscle regeneration and prevention of fibrosis. Muscle Nerve 2003, 28:365-372

14. Fukushima K, Badlani N, Usas A, Riano F, Fu F, Huard J: The use of an antifibrosis agent to improve muscle recovery after laceration. Am J Sports Med 2001, 29:394-402

15. Yamazaki M, Minota S, Sakurai H, Miyazono K, Yamada A, Kanazawa I, Kawai M: Expression of transforming growth factor-beta 1 and its relation to endomysial fibrosis in progressive muscular dystrophy. Am J Pathol 1994, 144:221-226

16. Li Y, Negishi S, Sakamoto M, Usas A, Huard J: The use of relaxin improves healing in injured muscle. Ann N Y Acad Sci 2005, 1041 : 395-397

17. Negishi S, Li Y, Usas A, Fu FH, Huard J: The effect of relaxin treatment on skeletal muscle injuries. Am J Sports Med 2005, 33:1816-1824
18. Bedair HS, Karthikeyan T, Quintero A, Li Y, Huard J: Angiotensin II receptor blockade administered after injury improves muscle regeneration and decreases fibrosis in normal skeletal muscle. Am J Sports Med 2008, 36:1548-1554

19. Bogdanovich S, Krag TO, Barton ER, Morris LD, Whittemore LA, Ahima RS, Khurana TS: Functional improvement of dystrophic muscle by myostatin blockade. Nature 2002, 420:418-421

20. McCroskery S, Thomas M, Platt L, Hennebry A, Nishimura T, McLeay L, Sharma M, Kambadur R: Improved muscle healing through enhanced regeneration and reduced fibrosis in myostatin-null mice. $J$ Cell Sci 2005, 118:3531-3541

21. Qiao C, Li J, Jiang J, Zhu X, Wang B, Xiao X: Myostatin propeptide gene delivery by adeno-associated virus serotype 8 vectors enhances muscle growth and ameliorates dystrophic phenotypes in mdx mice. Hum Gene Ther 2008, 19:241-254

22. Wagner KR, McPherron AC, Winik N, Lee SJ: Loss of myostatin attenuates severity of muscular dystrophy in mdx mice. Ann Neurol 2002, 52:832-836

23. Zhu J, Li Y, Shen W, Qiao C, Ambrosio F, Lavasani M, Nozaki M, Branca MF, Huard J: Relationships between transforming growth factor-beta1, myostatin, and decorin: implications for skeletal muscle fibrosis. J Biol Chem 2007, 282:25852-25863

24. Parsons SA, Millay DP, Sargent MA, McNally EM, Molkentin JD: Age-dependent effect of myostatin blockade on disease severity in a murine model of limb-girdle muscular dystrophy. Am J Pathol 2006, 168:1975-1985

25. McPherron AC, Lawler AM, Lee SJ: Regulation of skeletal muscle mass in mice by a new TGF-beta superfamily member. Nature 1997 , 387:83-90

26. Zimmers TA, Davies MV, Koniaris LG, Haynes P, Esquela AF, Tomkinson KN, McPherron AC, Wolfman NM, Lee SJ: Induction of cachexia in mice by systemically administered myostatin. Science 2002, 296:1486-1488

27. Li ZB, Kollias HD, Wagner KR: Myostatin directly regulates skeletal muscle fibrosis. J Biol Chem 2008, 283:19371-19378

28. Budasz-Rwiderska M, Jank M, Motyl T: Transforming growth factorbeta1 upregulates myostatin expression in mouse C2C12 myoblasts. J Physiol Pharmacol 2005, 56(Suppl 3):195-214

29. Miller TM, Kim SH, Yamanaka K, Hester M, Umapathi P, Arnson H, Rizo L, Mendell JR, Gage FH, Cleveland DW, Kaspar BK: Gene transfer demonstrates that muscle is not a primary target for non-cellautonomous toxicity in familial amyotrophic lateral sclerosis. Proc Natl Acad Sci U S A 2006, 103:19546-19551

30. Wagner KR, Fleckenstein JL, Amato AA, Barohn RJ, Bushby K, Escolar DM, Flanigan KM, Pestronk A, Tawil R, Wolfe GI, Eagle M, Florence JM, King WM, Pandya S, Straub V, Juneau P, Meyers K, Csimma C, Araujo T, Allen R, Parsons SA, Wozney JM, Lavallie ER, Mendell JR: A phase I/IItrial of MYO-029 in adult subjects with muscular dystrophy. Ann Neurol 2008, 63:561-571

31. Fainsod A, Deissler K, Yelin R, Marom K, Epstein M, Pillemer G, Steinbeisser $H$, Blum M: The dorsalizing and neural inducing gene follistatin is an antagonist of BMP-4. Mech Dev 1997, 63:39-50

32. Gamer LW, Wolfman NM, Celeste AJ, Hattersley G, Hewick R, Rosen $\mathrm{V}$ : A novel BMP expressed in developing mouse limb, spinal cord, and tail bud is a potent mesoderm inducer in Xenopus embryos. Dev Biol 1999, 208:222-232

33. Thompson TB, Lerch TF, Cook RW, Woodruff TK, Jardetzky TS: The structure of the follistatin: activin complex reveals antagonism of both type I and type II receptor binding. Dev Cell 2005, 9:535-543

34. Amthor H, Nicholas G, McKinnell I, Kemp CF, Sharma M, Kambadur $\mathrm{R}$, Patel K: Follistatin complexes myostatin and antagonises myostatin-mediated inhibition of myogenesis. Dev Biol 2004, 270:19-30

35. Lee SJ, McPherron AC: Regulation of myostatin activity and muscle growth. Proc Natl Acad Sci U S A 2001, 98:9306-9311

36. Nakatani M, Takehara $Y$, Sugino $H$, Matsumoto $M$, Hashimoto $O$, Hasegawa Y, Murakami T, Uezumi A, Takeda S, Noji S, Sunada Y, Tsuchida K: Transgenic expression of a myostatin inhibitor derived from follistatin increases skeletal muscle mass and ameliorates dystrophic pathology in mdx mice. FASEB J 2008, 22:477-487

37. Haidet AM, Rizo L, Handy C, Umapathi P, Eagle A, Shilling C, Boue D, Martin PT, Sahenk Z, Mendell JR, Kaspar BK: Long-term enhancement of skeletal muscle mass and strength by single gene administration of myostatin inhibitors. Proc Natl Acad Sci U S A 2008, 105: 4318-4322 
38. Benabdallah BF, Bouchentouf M, Rousseau J, Tremblay JP: Overexpression of follistatin in human myoblasts increases their proliferation and differentiation, and improves the graft success in SCID mice. Cell Transplant 2009, 18:709-718

39. Kota J, Handy CR, Haidet AM, Montgomery CL, Eagle A, RodinoKlapac LR, Tucker D, Shilling CJ, Therlfall WR, Walker CM, Weisbrode SE, Janssen PM, Clark KR, Sahenk Z, Mendell JR, Kaspar BK: Follistatin gene delivery enhances muscle growth and strength in nonhuman primates. Sci Transl Med 2009, 1:6-15

40. Lee SJ, Reed LA, Davies MV, Girgenrath S, Goad ME, Tomkinson KN, Wright JF, Barker C, Ehrmantraut G, Holmstrom J, Trowell B, Gertz B, Jiang MS, Sebald SM, Matzuk M, Li E, Liang LF, Quattlebaum E, Stotish RL, Wolfman NM: Regulation of muscle growth by multiple ligands signaling through activin type II receptors. Proc Natl Acad Sci U S A 2005, 102:18117-18122

41. Lee SJ, Lee YS, Zimmers TA, Soleimani A, Matzuk MM, Tsuchida K, Cohn RD, Barton ER: Regulation of muscle mass by follistatin and activins. Mol Endocrinol 2010, 24:1998-2008

42. Jankowski RJ, Haluszczak C, Trucco M, Huard J: Flow cytometric characterization of myogenic cell populations obtained via the preplate technique: potential for rapid isolation of muscle-derived stem cells. Hum Gene Ther 2001, 12:619-628

43. Qu-Petersen Z, Deasy B, Jankowski R, Ikezawa M, Cummins J, Pruchnic R, Mytinger J, Cao B, Gates C, Wernig A, Huard J: Identification of a novel population of muscle stem cells in mice: potential for muscle regeneration. J Cell Biol 2002, 157:851-864

44. Krneta J, Kroll J, Alves F, Prahst C, Sananbenesi F, Dullin C, Kimmina S, Phillips DJ, Augustin HG: Dissociation of angiogenesis and tumorigenesis in follistatin- and activin-expressing tumors. Cancer Res 2006, 66:5686-5695

45. Nguyen F, Guigand L, Goubault-Leroux I, Wyers M, Cherel Y: Microvessel density in muscles of dogs with golden retriever muscular dystrophy. Neuromuscul Disord 2005, 15:154-163

46. Deasy BM, Gharaibeh BM, Pollett JB, Jones MM, Lucas MA, Kanda Y, Huard J: Long-term self-renewal of postnatal muscle-derived stem cells. Mol Biol Cell 2005, 16:3323-3333

47. Olson EN, Sternberg E, Hu JS, Spizz G, Wilcox C: Regulation of myogenic differentiation by type beta transforming growth factor. J Cell Biol 1986, 103:1799-1805

48. Shen W, Li Y, Tang Y, Cummins J, Huard J: NS-398, a cyclooxygenase-2-specific inhibitor, delays skeletal muscle healing by decreasing regeneration and promoting fibrosis. Am J Pathol 2005, 167: 1105-1117

49. Ahn A, Frishman WH, Gutwein A, Passeri J, Nelson M: Therapeutic angiogenesis: a new treatment approach for ischemic heart diseasepart I. Cardiol Rev 2008, 16:163-171

50. Okada M, Payne TR, Zheng B, Oshima H, Momoi N, Tobita K, Keller BB, Phillippi JA, Peault B, Huard J: Myogenic endothelial cells purified from human skeletal muscle improve cardiac function after transplantation into infarcted myocardium. J Am Coll Cardiol 2008, 52: 1869-1880

51. Payne TR, Oshima H, Okada M, Momoi N, Tobita K, Keller BB, Peng $\mathrm{H}$, Huard J: A relationship between vascular endothelial growth factor, angiogenesis, and cardiac repair after muscle stem cell transplantation into ischemic hearts. J Am Coll Cardiol 2007, 50:16771684

52. Deasy BM, Feduska JM, Payne TR, Li Y, Ambrosio F, Huard J: Effect of VEGF on the regenerative capacity of muscle stem cells in dystrophic skeletal muscle. Mol Ther 2009, 17:1788-1798
53. Gao X, Hu H, Zhu J, Xu Z: Identification and characterization of follistatin as a novel angiogenin-binding protein. FEBS Lett 2007 , 581:5505-5510

54. Glienke J, Schmitt AO, Pilarsky C, Hinzmann B, Weiss B, Rosenthal A, Thierauch $\mathrm{KH}$ : Differential gene expression by endothelial cells in distinct angiogenic states. Eur J Biochem 2000, 267:2820-2830

55. Kozian DH, Ziche M, Augustin HG: The activin-binding protein follistatin regulates autocrine endothelial cell activity and induces angiogenesis. Lab Invest 1997, 76:267-276

56. Lin SY, Craythorn RG, O'Connor AE, Matzuk MM, Girling JE, Morrison JR, de Kretser DM: Female infertility and disrupted angiogenesis are actions of specific follistatin isoforms. Mol Endocrinol 2008, 22:415-429

57. McCarthy SA, Bicknell R: Inhibition of vascular endothelial cell growth by activin-A. J Biol Chem 1993, 268:23066-23071

58. Jarvinen M: Healing of a crush injury in rat striated muscle. 3. A micro-angiographical study of the effect of early mobilization and immobilization on capillary ingrowth. Acta Pathol Microbiol Scand A 1976, 84:85-94

59. Jozsa L, Reffy A, Demel S, Szilagyi I: Alterations of oxygen and carbon dioxide tensions in crush-injured calf muscles of rat. Z Exp Chir 1980, 13:91-94

60. Jarvinen TA, Kaariainen $M$, Jarvinen $M$, Kalimo $H$ : Muscle strain injuries. Curr Opin Rheumatol 2000, 12:155-161

61. Gros J, Manceau M, Thome V, Marcelle C: A common somitic origin for embryonic muscle progenitors and satellite cells. Nature 2005, 435:954-958

62. Kassar-Duchossoy L, Giacone E, Gayraud-Morel B, Jory A, Gomes D, Tajbakhsh S: Pax3/Pax7 mark a novel population of primitive myogenic cells during development. Genes Dev 2005, 19:1426-1431

63. Relaix F, Rocancourt D, Mansouri A, Buckingham M: A Pax3/Pax7dependent population of skeletal muscle progenitor cells. Nature 2005, 435:948-953

64. Le Grand F, Rudnicki MA: Skeletal muscle satellite cells and adult myogenesis. Curr Opin Cell Biol 2007, 19:628-633

65. McCroskery S, Thomas M, Maxwell L, Sharma M, Kambadur R: Myostatin negatively regulates satellite cell activation and self-renewal. J Cell Biol 2003, 162:1135-1147

66. McFarlane C, Hennebry A, Thomas M, Plummer E, Ling N, Sharma M, Kambadur R: Myostatin signals through Pax7 to regulate satellite cell self-renewal. Exp Cell Res 2008, 314:317-329

67. Deasy BM, Lu A, Tebbets JC, Feduska JM, Schugar RC, Pollett JB, Sun B, Urish KL, Gharaibeh BM, Cao B, Rubin RT, Huard J: A role for cell sex in stem cell-mediated skeletal muscle regeneration: female cells have higher muscle regeneration efficiency. J Cell Biol 2007. 177:73-86

68. Kunkel LM, Beggs AH, Hoffman EP: Molecular genetics of Duchenne and Becker muscular dystrophy: emphasis on improved diagnosis. Clin Chem 1989, 35:B21-24

69. Bieber FR, Hoffman EP: Duchenne and Becker muscular dystrophies: genetics, prenatal diagnosis, and future prospects. Clin Perinatol 1990, 17:845-865

70. Benabdallah BF, Bouchentouf M, Rousseau J, Bigey P, Michaud A, Chapdelaine P, Scherman D, Tremblay JP: Inhibiting myostatin with follistatin improves the success of myoblast transplantation in dystrophic mice. Cell Transplant 2008, 17:337-350

71. Gilson H, Schakman O, Kalista S, Lause P, Tsuchida K, Thissen JP: Follistatin induces muscle hypertrophy through satellite cell proliferation and inhibition of both myostatin and activin. Am J Physiol Endocrinol Metab 2009, 297:E157-164

72. Lee SJ: Quadrupling muscle mass in mice by targeting TGF-beta signaling pathways. PLoS ONE 2007, 2:e789 